\title{
Legionella pneumophila Secretes a Mitochondrial Carrier Protein during Infection
}

\author{
Pavel Dolezal ${ }^{1,2}$, Margareta Aili ${ }^{3 x}$, Janette Tong ${ }^{1}$, Jhih-Hang Jiang ${ }^{1,3}$, Carlo M. Marobbio ${ }^{4}$, Sau fung Lee ${ }^{3}$, \\ Ralf Schuelein ${ }^{3}$, Simon Belluzzo ${ }^{3}$, Eva Binova ${ }^{5}$, Aurelie Mousnier ${ }^{6}$, Gad Frankel ${ }^{6}$, Giulia Giannuzzi ${ }^{4}$, \\ Ferdinando Palmieri ${ }^{4}$, Kipros Gabriel ${ }^{1}$, Thomas Naderer ${ }^{1}$, Elizabeth L. Hartland ${ }^{3 *}$, Trevor Lithgow ${ }^{1}{ }^{*}$
}

1 Department of Biochemistry and Molecular Biology, Monash University, Clayton, Australia, 2 Department of Parasitology, Charles University, Prague, Czech Republic, 3 Department of Microbiology and Immunology, University of Melbourne, Parkville, Australia, 4 Department of Pharmaco-Biology, Laboratory of Biochemistry and Molecular Biology, University of Bari, Bari, Italy, $\mathbf{5}$ Department of Tropical Medicine, 1st Faculty of Medicine, Charles University in Prague and Faculty Hospital Bulovka, Prague, Czech Republic, 6 Centre for Molecular Microbiology and Infection, Division of Cell and Molecular Biology, Imperial College London, London, United Kingdom

\begin{abstract}
The Mitochondrial Carrier Family (MCF) is a signature group of integral membrane proteins that transport metabolites across the mitochondrial inner membrane in eukaryotes. MCF proteins are characterized by six transmembrane segments that assemble to form a highly-selective channel for metabolite transport. We discovered a novel MCF member, termed Legionella nucleotide carrier Protein (LnCP), encoded in the genome of Legionella pneumophila, the causative agent of Legionnaire's disease. LncP was secreted via the bacterial Dot/lcm type IV secretion system into macrophages and assembled in the mitochondrial inner membrane. In a yeast cellular system, LncP induced a dominant-negative phenotype that was rescued by deleting an endogenous ATP carrier. Substrate transport studies on purified LncP reconstituted in liposomes revealed that it catalyzes unidirectional transport and exchange of ATP transport across membranes, thereby supporting a role for LncP as an ATP transporter. A hidden Markov model revealed further MCF proteins in the intracellular pathogens, Legionella longbeachae and Neorickettsia sennetsu, thereby challenging the notion that MCF proteins exist exclusively in eukaryotic organisms.
\end{abstract}

Citation: Dolezal P, Aili M, Tong J, Jiang J-H, Marobbio CM, et al. (2012) Legionella pneumophila Secretes a Mitochondrial Carrier Protein during Infection. PLoS Pathog 8(1): e1002459. doi:10.1371/journal.ppat.1002459

Editor: Craig R. Roy, Yale University School of Medicine, United States of America

Received June 10, 2011; Accepted November 9, 2011; Published January 5, 2012

Copyright: $\odot 2012$ Dolezal et al. This is an open-access article distributed under the terms of the Creative Commons Attribution License, which permits unrestricted use, distribution, and reproduction in any medium, provided the original author and source are credited.

Funding: This work was funded by grants from the Ministero dell'Università e della Ricerca (MIUR), the Center of Excellence in Genomics (CEGBA), Fondazione Cassa di Risparmio di Puglia, the Italian Human ProteomeNet No. RBRN07BMCT_009 (MIUR), Czech Science Foundation grant P305/10/0651, Program Grant (606788) from the National Health and Medical Research Council (NHMRC) of Australia, the Australian Research Council (ARC) and the Wellcome Trust. MA was supported by a Wenner-Gren Foundation Fellowship, SB by an Australian Postgraduate Award and JHJ by an Endeavor Postgraduate Award. ELH is an ARC Future Fellow, TL is an ARC Federation Fellow. The funders had no role in study design, data collection and analysis, decision to publish, or preparation of the manuscript.

Competing Interests: The authors have declared that no competing interests exist.

*E-mail: hartland@unimelb.edu.au (ELH); trevor.lithgow@monash.edu (TL)

a Current address: Uppsala BioCenter, Department of Plant Biology and Forest Genetics, The Swedish University of Agricultural Sciences (SLU), Uppsala, Sweden

\section{Introduction}

Legionella pneumophila is an intracellular pathogen and the major causative agent of Legionnaire's disease, an acute form of pneumonia. The ability of the bacteria to replicate in environmental protozoa such as amoebae has equipped the bacteria with the capacity to replicate in human alveolar macrophages, leading to lung inflammation and disease [1,2]. Within macrophages and amoebae, the bacteria replicate within a membrane bound vacuole, block phagolysosome fusion and intercept vesicles trafficking in the secretory pathway [3,4]. Mitochondria are also transiently recruited to the L. pneumophila intracellular compartment [5]. The membrane of the mature Legionella-containing vacuole (LCV) shares many characteristics with membrane of the rough endoplasmic reticulum, reviewed in [6,7] but interactions with the endocytic pathway are also evident [8]. Therefore formation of the intracellular replicative niche of $L$. pneumophila results from extensive remodelling of the intracellular vacuole and multiple interactions with vesicle trafficking pathways within the host cell $[8,9]$.

The formation of the LCV relies on a functional bacterial Dot/ Icm Type IVB secretion system, which delivers at least 275 effectors into the host cell cytosol [10-13]. The effectors target multiple host cell functions including GTPase activity, ubiquitination, phosphoinositide metabolism, eukaryotic protein translation, autophagy and apoptosis, reviewed in [6,14-17]. Many groups of effectors have overlapping and somewhat redundant activities making the use of reverse bacterial genetics to identify gene function difficult. Instead, many investigators have applied cell biology and protein biochemistry techniques to understand the biochemical activity of Dot/Icm effectors and their possible role during LGV formation and $L$. pneumophila intracellular replication [18-21].

Genomics has revealed that a substantial number of Dot/Icm effectors share similarity with eukaryotic proteins [22]. For example, a large group of effectors contain multiple ankyrin repeat domains [23] and another group share similarity with Fbox and U-box proteins involved in protein ubiquitination [2426]. One effector termed LegS2 shares amino acid sequence similarity with eukaryotic sphingosine-1-phosphate lyases and is targeted to mitochondria during infection [27], although the importance of this targeting to LegS2 function is unknown.

In this study, we discovered that the genome of L. pneumophila strain $130 \mathrm{~b}$ encodes a putative member of the Mitochondrial 


\section{Author Summary}

Mitochondrial carrier proteins evolved during endosymbiosis to transport substrates across the mitochondrial inner membrane. As such the proteins are associated exclusively with eukaryotic organisms. Despite this, we identified putative mitochondrial carrier proteins in the genomes of different intracellular bacterial pathogens, including Legionella pneumophila, the causative agent of Legionnaire's disease. We named the mitochondrial carrier protein from L. pneumophila LncP and determined that the protein is translocated into host cells during infection by the bacterial Dot/lcm type IV secretion system. From there, LncP accesses the classical mitochondrial import pathway and is incorporated into the mitochondrial inner membrane as an integral membrane protein. Remarkably, LncP crosses five biological membranes to reach its final location. Biochemically, LncP is a unidirectional nucleotide transporter similar to Aac1 in yeast. Although not essential for intracellular replication, the high carriage rate of $\operatorname{Inc} P$ among isolates of $L$. pneumophila suggests that the ability of the pathogen to manipulate mitochondrial ATP transport assists survival of the bacteria in an intracellular environment.

Carrier Family (MCF), termed LncP for Legionella nucleotide carrier Protein. MCF proteins are a signature family of eukaryotic proteins that evolved in the course of endosymbiosis, ultimately giving rise to mitochondria [28]. MCF proteins are found in the broadest distribution of eukaryotes, including humans, yeast, plants and parasites such as trypanosomes and amoebae [29-32]. In humans, yeast and other eukaryotes, MCF proteins are synthesized in the cytoplasm and enter mitochondria via a defined "carrier pathway". The proteins are chaperoned through the cytosol by Hsp70/Hsp90 and delivered to the Tom70 receptor on the mitochondrial surface [33]. After threading through the channel in the outer mitochondrial membrane, unfolded MCFs are bound by the TIM9:10 chaperone in the intermembrane space and then assembled into the mitochondrial inner membrane by the TIM22 complex (reviewed in [34-37]). Here we found that LncP was translocated into host cells by the Dot/Icm type IV secretion system and transported into the mitochondrial inner membrane by the mitochondrial TIM9:10 chaperones and the TIM22 complex. A yeast model system and biochemical transport assays suggested that LncP mediated the unidirectional transport of ATP. In this otherwise exclusively eukaryotic group of proteins, LncP is the first example of a MCF member from bacteria that may contribute to the persistence of $L$. pneumophila within eukaryotic cells.

\section{Results}

\section{Legionella pneumophila Encodes a Putative Mitochondrial Carrier Protein}

When the UniProt data set of protein sequences was screened with a hidden Markov model for mitochondrial carrier family (MCF) proteins, an expected number of MCF proteins were detected in mammals, plants and fungi [38-42] and a smaller number in protists such as Entamoeba histolytica [32]. Unexpectedly, a handful of protein sequences was also retrieved from bacteria. Two of these were encoded in the genome of the intracellular pathogen Neorickettsia sennetsu, the causative agent of Sennetsu fever $[43,44]$. Three other carriers were encoded in the genome of $L$. longbeachae (Llo1924, Llo3082 and Llo1358), with Llo1924 having a homolog (sequence identity of $57 \%$; Figure 1A), encoded in the genome of the related pathogen L. pneumophila strain 130b (openreading frame LPW_31961) [45,46]. The putative MCF protein from L. pneumophila was subsequently termed LncP.

The crystal structure of the prototypical MCF, the adenine nucleotide transporter from mammals, shows that the protein has six transmembrane segments that are embedded in the mitochondrial inner membrane [47]. Bioinformatic analysis indicated that the amino acid sequences of Llo1924 and LncP had six predicted transmembrane segments and a three-fold repeated signature motif (Figure 1A) which are the essential characteristics of members of the MCF (Figure 1B) [38-42]. MCF proteins differ to nucleotide carriers in the inner membranes of the Chlamydiales and the Rickettsiales, which represent different family of proteins, referred to as TLC ATP/ADP transporters (PF03219) [48,49]. This latter group is of bacterial origin, and has spread from chlamydial ancestors to other classes of bacteria and to chloroplasts via lateral gene transfer events. TLC ATP/ADP transporters contain twelve transmembrane segments and their nucleotide exchange properties do not require membrane potential [50].

\section{LncP Is Targeted to Mitochondria during Infection in a Dot/lcm T4SS-dependent Manner}

Many eukaryotic-type proteins from L. pneumophila are translocated into infected cells via the Dot/Icm type IV secretion system. To determine if $\mathrm{LncP}$ was a Dot/Icm effector, we generated a translational fusion of the calmodulin-dependent adenylate cyclase from Bordetella pertussis (CyaA), with the N-terminus of LncP (Cya$\mathrm{LncP}$ ). The Cya-LncP fusion construct was introduced into wild type L. pneumophila $130 \mathrm{~b}$ or a $\operatorname{dot} / \mathrm{icm}(\operatorname{dotA})$ mutant [51]. Upon infection of THP-1 macrophages, Cya-LncP translocation was detected by increased cyclic AMP (cAMP) production at levels similar to the positive control (Cya-RalF) (Figure 2A). This translocation was dependent on $\operatorname{dot} A$ indicating that $\mathrm{LncP}$ is a Dot/Icm effector. Compared to eukaryotic MCF members, LncP carries a short amino acid extension at the C-terminus (Figure 1A). As the secretion signal for many Dot/Icm effectors lies in the Gterminus of the protein [52,53], we tested whether this region contained a Dot/Icm secretion signal, however deletion of the Cterminal amino acid residues PTRKR had no effect on Dot/Icm dependent translocation (Figure 2A).

To determine if LncP localized to mitochondria during infection of macrophages, we generated a $4 \mathrm{HA}$ epitope-tagged version of LncP for expression in L. pneumophila. The resulting expression plasmid, p4HA-LncP, was transformed into wild type $L$. pneumophila $130 \mathrm{~b}$ and the dotA mutant. Upon infection of macrophages for $5 \mathrm{~h}$ with $130 \mathrm{~b}$ carrying $\mathrm{p} 4 \mathrm{HA}-\mathrm{LncP}$, anti-HA staining co-localized extensively with Mitotracker red in infected cells (Figure 2B). Anti-HA staining was not observed in macrophages infected with $L$. pneumophila 130 b carrying the empty vector, pICC562, or in macrophages infected with the dotA mutant carrying p4HA-LncP (Figure 2B). Similar results were observed upon L. pneumophila infection of HeLa cells (Figure S1). We detected increasing amounts of $\mathrm{LncP}$ associated with mitochondria over time (Figure 2C) and at earlier time points, we frequently observed LncP staining at the poles of the bacterial cell where the Dot/Icm secretion system is believed to be located (Figure 2C). Altogether, this demonstrated that LncP was localized to mitochondria during L. pneumophila infection and this event relied upon a functional dot/icm system.

Many genes encoding Dot/Icm effectors are dispensable for intracellular replication due to functional redundancy [9], reviewed in [6]. Likewise here, the gene encoding $\mathrm{LncP}$ was not required for L. pneumophila $130 \mathrm{~b}$ intracellular replication in 

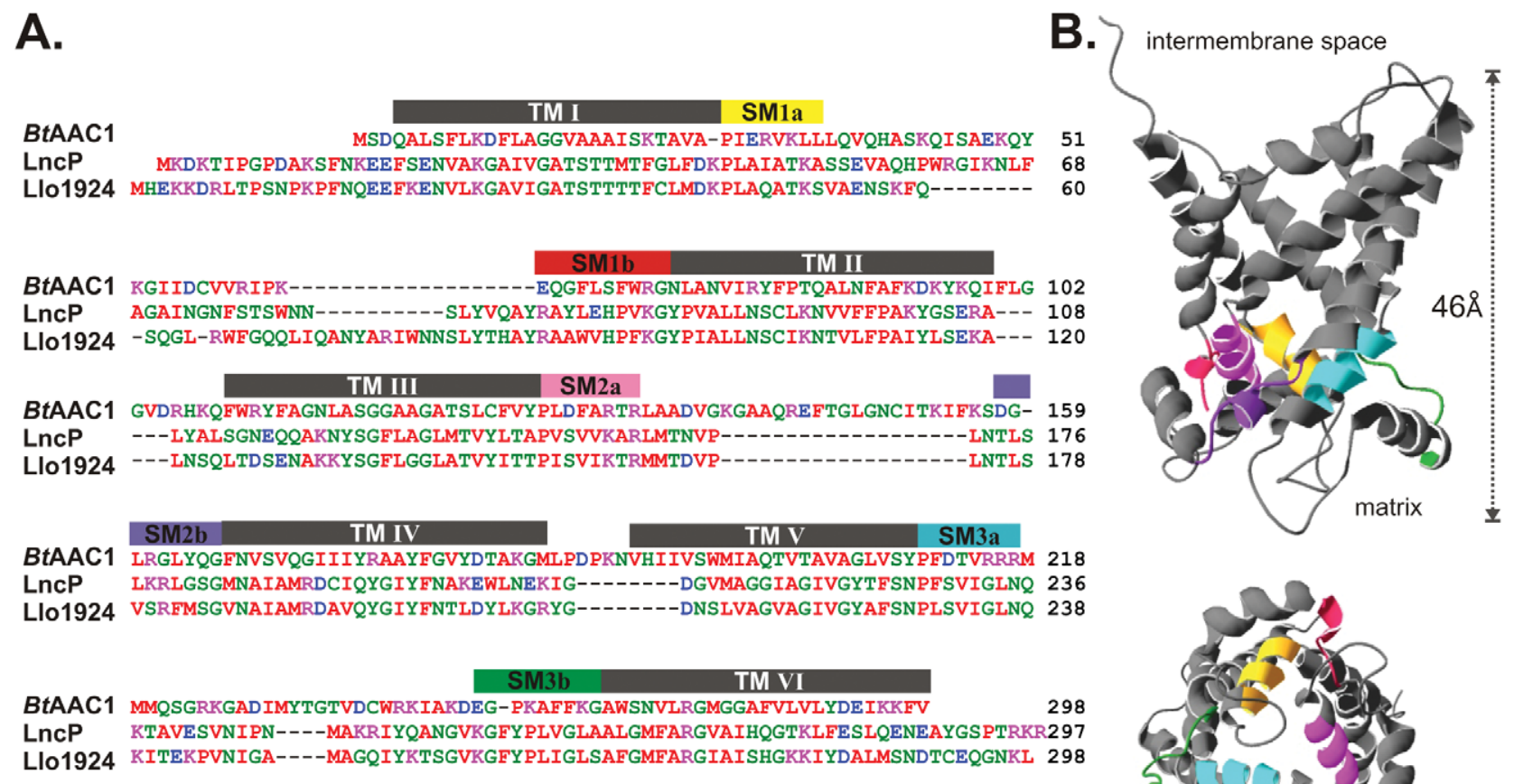

$\begin{array}{ll}\text { BtAAC1 } & \text { LRGLYQGFNVSVQGIIIYRAAYFGVYDTAKGMLPDPKNVHIIVSWMIAQTVTAVAGLVSYPFDTVRRRM } 218 \\ \text { LncP } & \text { LKRLGSGMNAIAMRDCIQYGIYFNAKEWLNEKIG-------DGVMAGGIAGIVGYTFSNPFSVIGLNQ } 236 \\ \text { Llo1924 VSRFMSGVNAIAMRDAVQYGIYFNTLDYLKGRYG-------DNSLVAGVAGIVGYAFSNPLSVIGLNQ } 238\end{array}$

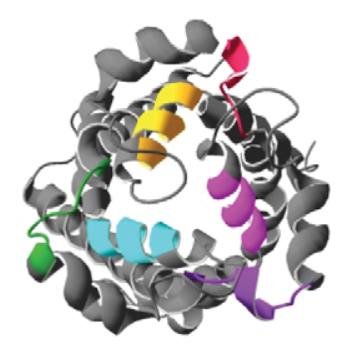

Figure 1. A mitochondrial carrier protein in Legionella. (A) Sequence alignment of LncP from L. pneumophila and Llo1924 from L. longbeachae with the ADP/ATP carrier from Bos taurus. Amino acid residues are colored red (hydrophobic), blue (acidic), magenta (basic), green (polar) and the six predicted transmembrane segments shown. Conservation is seen through the predicted transmembrane segments and in the three-fold repeated signature motif (labeled SM1a-SM1b, SM2a-SM2b, SM3a-SM3b), all of which are characteristic of all members of the mitochondrial carrier protein family $[40,41]$. (B) The three-dimensional structure of the ADP/ATP carrier from B. taurus (PDB: 1OKC), with the three-fold repeated signature motif color-coded as shown in Figure 1A. The folded protein has a "height" of $46 \AA$ and the maximum "width" dimension is $41 \AA$. doi:10.1371/journal.ppat.1002459.g001

THP-1 macrophages (Figure 3A) or in the model amoeba, Acanthamoeba castellanii (Figure 3B). However, PGR screening of 37 distinct $L$. pneumophila isolates detected the gene encoding $\mathrm{LncP}$ in 28 of these strains (Table S1). The high carriage rate $(\sim 75 \%)$ of the $\operatorname{lncP}$ gene among L. pneumophila strains strongly suggests LncP provides a competitive advantage during interactions with host cells.

\section{LncP Is an Integral Mitochondrial Inner Membrane Protein}

Fluorescence microscopy confirmed that GFP-LncP was targeted to mitochondria when expressed ectopically in HeLa cells (Figure 4A). This substantiates a model whereby cytosolic LncP can access the mitochondrial import machinery in mammalian cells. To test whether LncP was imported by mitochondria, the putative MCF protein was translated in vitro and incubated with mitochondria isolated from yeast. This represents the best experimental system to characterize the pathway by which LncP is imported into mitochondria. LncP was imported into mitochondria and protected from Proteinase $\mathrm{K}$ treatment showing that it is not imported into the mitochondrial outer membrane (Figure 4B). Import of mitochondrial carrier proteins is reliant on a membrane potential across the inner membrane. Here pretreatment of mitochondria with CCCP, that dissipates the transmembrane potential $\left(\Delta \psi_{\mathrm{m}}\right)$, also inhibited LncP import (Figure $4 \mathrm{~B}$, “ $-\Delta \psi "$ "). Imported LncP behaved as an integral inner membrane protein similar to Tim23, being largely resistant to alkali extraction, unlike the non-membrane embedded, matrix targeted protein, $\mathrm{F}_{1} \beta$ (Figure $4 \mathrm{G}$ ).
The TIM9:10 chaperone characteristically binds carrier proteins during the initial phase of their assembly in the inner mitochondrial membrane. Blue-native (BN)-PAGE analysis of imported phosphate carrier PiC (Figure 4D) and Aacl (data not shown) showed intermediate forms of the carrier during its import pathway and final assembly as a mature dimer complex. Folded PiC mostly existed as the dimeric (Stage V) form with only a small amount of folded monomer detected. LncP was also assembled in mitochondria efficiently but much of the folded protein accumulated as monomeric protein, possibly because there was no preexisting LncP in mitochondria with which imported LncP could oligomerise. The folding of carrier proteins is dependent on the TIM9:10 chaperone [54-56]. Mitochondria from a tim10 "shutdown" strain were not able to assemble $\mathrm{LncP}$ or $\mathrm{PiC}$ into complexes detectable by BN-PAGE (Figure 4D). Consistent with this finding, mitochondria from a tim10 "shut-down" strain, imported both $\mathrm{PiC}$ and $\mathrm{LncP}$ to a protease protected location at a greatly reduced efficiency (Figure 4E). When ImageQuant was used to compare the band intensities in lanes from wild-type and tim10 mutant mitochondria, the percentage decrease of import for both $\mathrm{PiC}$ and $\mathrm{LncP}$ was between $20 \%$ and $35 \%$ of wild-type (data not shown). In order to show the localization of mitochondrial proteins unambiguously it is possible to sequentially rupture the mitochondrial outer membrane (mitoplasting) or both membranes and test for sensitivity to protease digestion. Since these protease treatments are sensitive to rough handling, the digestion was performed in duplicate. LncP was degraded by Proteinase $\mathrm{K}$ after rupture of the outer membrane (Figure 4G). This characteristic is consistent with that of Tim23, an integral inner membrane protein 
A

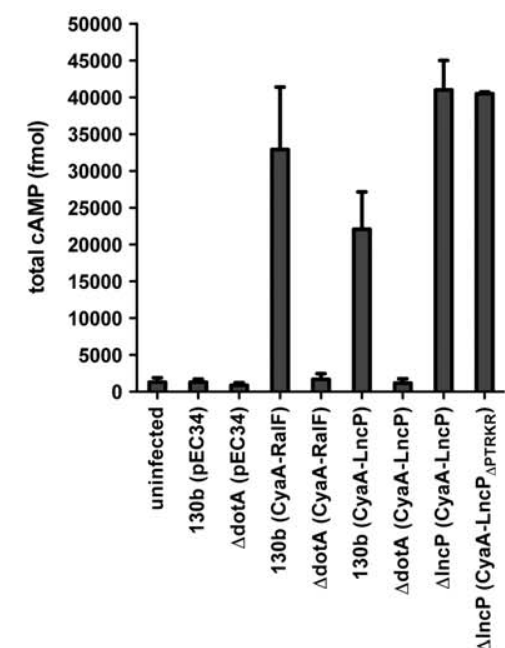

B

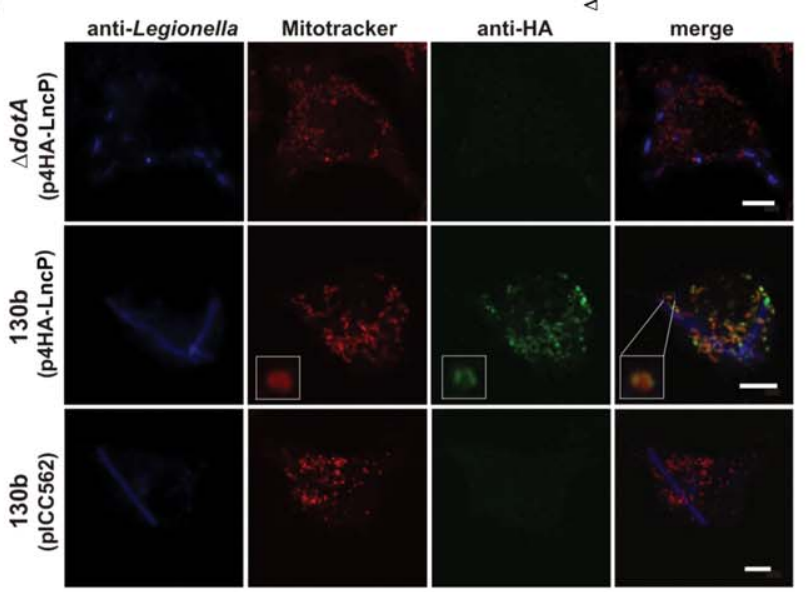

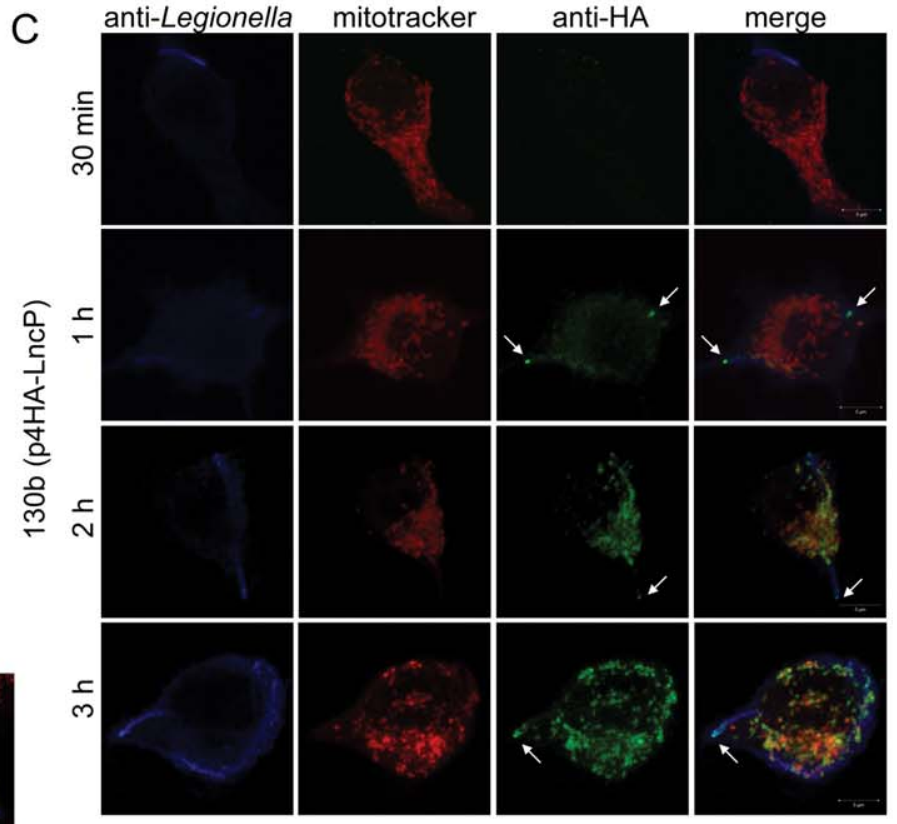

Figure 2. LncP is translocated into macrophages by the Dot/lcm T4SS. (A) THP-1 macrophages were left uninfected or infected with derivatives of $L$. pneumophila 130b carrying the pEC34 vector or expressing the indicated Cya hybrid proteins. Following infection for 1 hour, macrophages were lysed and total intracellular CAMP was measure by ELISA. Results are expressed as fmol cAMP and are the mean \pm standard deviation of three independent experiments, each performed in duplicate. Note Cya-LnCP ${ }_{\triangle P T R K R}$ is a truncated protein lacking the C-terminal residues (PTRKR) of LncP. (B) Immortalized macrophages from C57BL/6 mice were infected with derivatives of L. pneumophila $130 \mathrm{~b}$ for $5 \mathrm{~h}$ as indicated. Bacteria were visualized using anti-Legionella antibodies (blue) 4HA-LncP was visualized with antibodies to HA (green). Prior to fixation, cells were stained with MitoTracker Red. Cells were viewed by confocal microscopy under a $100 \times$ objective. White scale bars represent $5 \mu \mathrm{m}$. (C) Immortalized macrophages from C57BL/6 mice were infected with derivatives of L. pneumophila 130b for $30 \mathrm{~min}, 1 \mathrm{~h}, 2 \mathrm{~h}$ or $3 \mathrm{~h}$ as indicated, stained as above, and viewed by confocal microscopy under a $100 \times$ objective. White scale bars represent $5 \mu \mathrm{m}$. Arrows indicate LncP at the poles of the bacterial cell. doi:10.1371/journal.ppat.1002459.g002

with domains exposed to the intermembrane space. The matrix targeted protein, $\mathrm{F}_{1} \beta$ was not degraded by Proteinase $\mathrm{K}$ unless the inner membrane was also ruptured by the addition of detergent (Figure 4G). Slight changes in band intensity from lane to lane were not significant upon repetition, rather protease treatment drastically altered the levels of susceptible proteins such as after mitoplasting or treatment with detergent (Figure 4G).

\section{LncP Is a Nucleotide Carrier Protein}

Saccharomyces cerevisiae encodes 35 mitochondrial carrier proteins, including four proteins that can transport ATP: Aac1, Aac2, Aac3 and Sall [57] (Figure 5A). Yeast is a powerful model system to study cellular phenotypes, and fluorescence microscopy showed that ectopically expressed $\mathrm{LncP}$ is targeted to mitochondria in yeast (Figure 5B). Mutant yeast strains, each lacking one of these 35 carriers were transformed with a plasmid-based LncP expression construct and the transformed cells tested for growth complementation. The mutants were scored under conditions where characteristic growth defects were known. However no complementation was observed upon LncP expression in any of the mutants tested. For example, $\Delta a g c 1$ mutant cells lacking the amino acid transporter Agcl form only microcolonies on rich medium with glycerol as a carbon source; expression of LncP did not complement this growth defect (Figure 5C). However, we noted a dominant-negative phenotype from expression of $\mathrm{LncP}$ in wild-type cells which represented a 5-fold loss in viability on rich growth medium, exacerbated to $\sim 500$-fold loss of viability on minimal medium (Figure 5D). We therefore screened the carrier mutant collection for mutants resistant to this LncP-induced inhibition of cell viability. Only the $\Delta$ aac 1 mutant was resistant to the dominant-negative effect of LncP expression (Figure 5E). In yeast, Sall is a $\mathrm{Ca}^{2+}$-dependent ATP-import carrier that cotransports ATP and $\mathrm{Mg}^{2+}$ into the matrix during growth on glucose [58,59], and the Aacl transporter balances this effect by ATP export. The most likely explanation for the Aacldependent dominant-negative effect of LncP expression is that combined export of ATP from the matrix by LncP and Aacl 

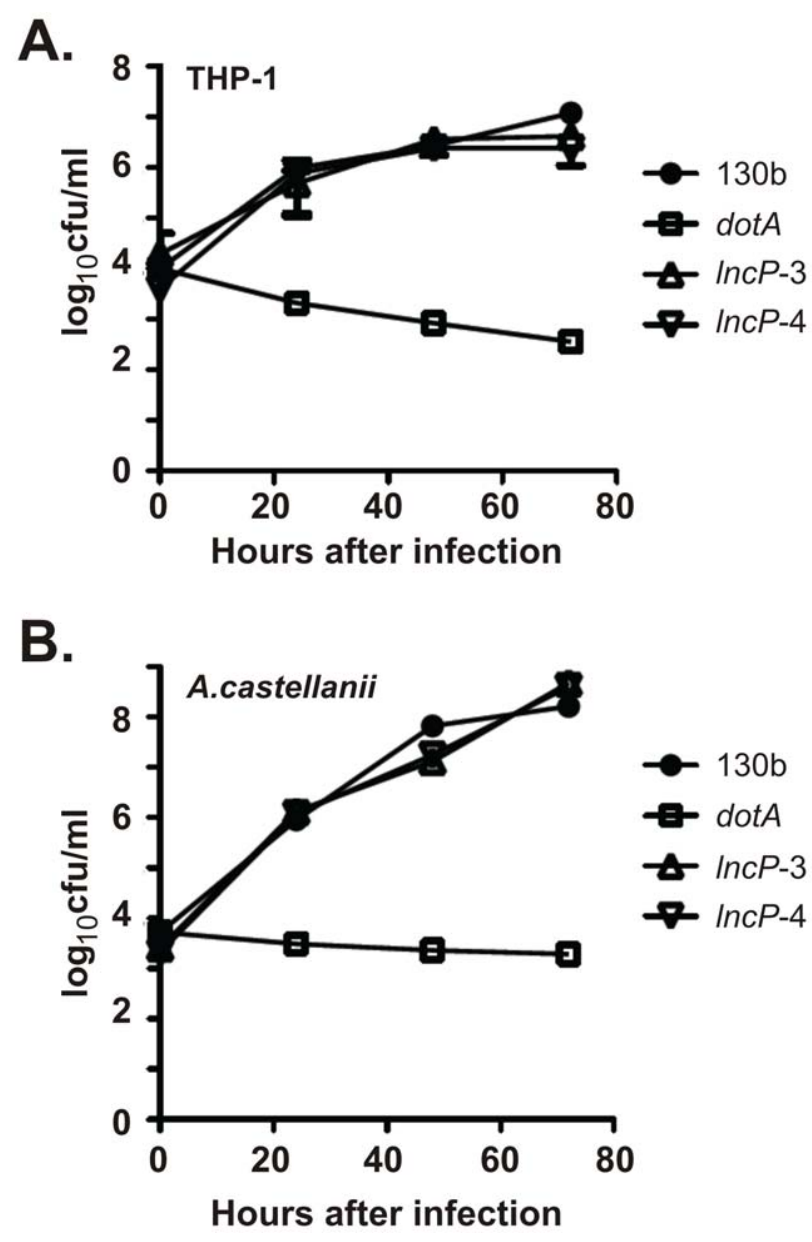

Figure 3. Mutant L. pneumophila lacking LncP replicate proficiently in host cells. Two independent mutants of $L$. pneumophila 130b lacking LncP (IncP-3 and IncP-4) were tested, along with a $\operatorname{dot} A$ mutant lacking the Dot/lcm T4SS. Replication of $L$. pneumophila $130 \mathrm{~b}(\bullet), \operatorname{Inc} P-3(\Delta), \operatorname{Inc} P-4(\nabla)$ and $\operatorname{dot} A(\square)$ within the macrophage cell-line THP-1 (A) and A. castellanii (B) is shown. Results are expressed as the $\log _{10} \mathrm{CFU}$ of viable bacteria present in the extracellular medium (and associated with cells for THP-1) at specific time points after inoculation, mean \pm standard deviation of at least three independent experiments from duplicate wells.

doi:10.1371/journal.ppat.1002459.g003

leads to a growth defect. Thus, yeast can tolerate the expression of Aacl or LncP, but not both of these carrier proteins.

In order to measure directly substrate transport catalyzed by LncP, purified recombinant protein was reconstituted into liposomes. LncP transported nucleotides, phosphate and pyrophosphate, with a strong preference for ATP and GTP (Figure 6A). The kinetic constants of purified reconstituted LncP were determined by measuring the initial transport rate at various external $\left[{ }^{3} \mathrm{H}\right] \mathrm{ATP}$ or $\left[{ }^{3} \mathrm{H}\right] \mathrm{GTP}$ concentrations in the presence of a fixed saturating internal concentration of ATP or GTP, respectively. The transport affinities $\left(\mathrm{K}_{\mathrm{m}}\right)$ of LncP for ATP and GTP were $190 \pm 37$ and $183 \pm 32 \mu \mathrm{M}$, respectively. The average $V_{\max }$ values for ATP and GTP were $926 \pm 216$ and $688 \pm 213 \mu \mathrm{mol} / \mathrm{min}$ $\mathrm{x} g$ of protein, respectively (mean values of 4 experiments).

Powerful inhibitors of the well-characterized ADP/ATP carrier, which transports only ADP and ATP, fix the transporter in a specific state: atractylosides (such as carboxyatractyloside; CAT) fixes the transporter in the "cytosolic" c-state thereby inducing swelling of mitochondria and apoptosis, and bongkrekic acid
(BKA) fixes the transporter in the "matrix" m-state thereby suppressing induction of apoptosis [60]. LncP was not inhibited by CAT or BKA (Figure 6B). It was also not inhibited by the $\mathrm{SH}$ alkylating reagent N-ethylmaleimide (NEM; inhibitor of the phosphate, glutamate and ornithine carriers). In contrast, ATP transport catalyzed by $\mathrm{LncP}$ was effectively prevented by other reagents such as mersalyl (MER), p-hydroxymercurybenzoate (p$\mathrm{HMB}$ ) and $\mathrm{HgCl} 2$, which are organic mercurials, and by pyridoxal-5'-phosphate (PLP) and bathophenanthroline (BAT), which alone or in combination inhibit the activity of several mitochondrial carriers, although their mechanism of action is not known. Therefore, both the substrate specificity (Figure 6A) and the inhibitor sensitivity (Figure 6B) of LncP distinguish it biochemically from the ADP/ATP carrier.

To characterize further the transport properties of LncP, the kinetics of $\left[{ }^{3} \mathrm{H}\right] \mathrm{ATP}$ and $\left[{ }^{3} \mathrm{H}\right] \mathrm{GTP}$ uptake into proteoliposomes were compared either as uniport (in the absence of internal substrate) or as exchange (in the presence of internal ATP or GTP, respectively) (Figure 6C). Both the exchange and the uniport reactions of ATP and GTP uptake followed first-order kinetics, isotopic equilibrium being approached exponentially. The ratio of maximal substrate uptake by both reactions was 9.8 for ATP and 13.0 for GTP, in good agreement with the expected ratio of 10 from the intraliposomal concentrations at equilibrium $(1 \mathrm{mM}$ and $10 \mathrm{mM}$ for uniport and exchange, respectively). The uniport mode of transport of reconstituted LncP was also investigated by measuring the efflux of $\left[{ }^{3} \mathrm{H}\right]$ ATP from pre-labeled proteoliposomes (Figure 6D) because this approach provides a more sensitive assay for unidirectional transport [61]. A significant efflux of ATP was observed in the absence of external substrate (filled circle) and a more rapid and extensive efflux occurred upon addition of ATP (open square) or phosphate (open triangle). Moreover, the ATPinduced efflux of radioactivity was prevented by the presence of the carrier inhibitors PLP and BAT (filled square). Similar results were obtained using GTP as substrate (data not shown). Thus, LncP was able to catalyze unidirectional transport of ATP and GTP and a fast exchange reaction of substrates.

\section{Discussion}

Recently, 275 effectors of the Dot/Icm secretion system were described in the Philadelphia-1 strain of L. pneumophila [13]. This represents almost $10 \%$ of all open reading frames encoded in the L. pneumophila genome. Given that there is also diversity in the presence and range of effector genes among the different sequenced L. pneumophila genomes and even greater differences between Legionella species [22], the total Dot/Icm effector repertoire is likely to be much larger. Here we describe a new Dot/Icm effector from L. pneumophila, LncP, with sequence and functional similarity to eukaryotic mitochondrial carrier proteins. LncP was predicted to have six transmembrane domains, similar to eukaryotic MCF members. Remarkably, this highly hydrophobic protein crosses five biological membranes to reach its final destination in the mitochondrial inner membrane. Generally bacterial membrane proteins are assembled into the cytoplasmic membrane by YidC and SecYEG [62], reviewed in [63]. Chaperones for the Dot/Icm machinery, such as IcmS, IcmW and LvgA [64-66], must be in active competition with the bacterial YidC/SecYEG machinery to dictate which integral membrane proteins will be assembled into the bacterial inner membrane and which will be evacuated via the Dot/Icm T4SS. Therefore recognition of LncP by the Dot/Icm machinery presumably allows this hydrophobic protein to avoid assembly into the bacterial inner membrane by YidC/SecYEG (Figure 7). 
A.
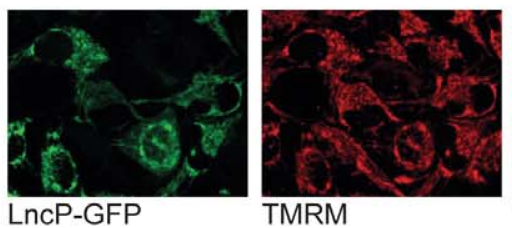

TMRM

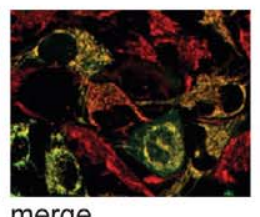

merge
B.

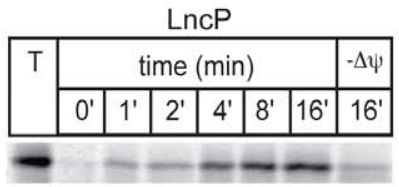

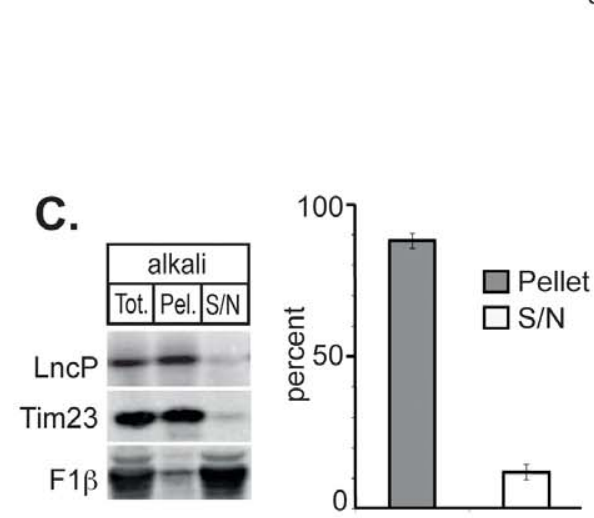
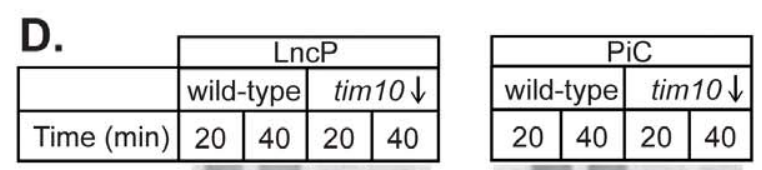

F.

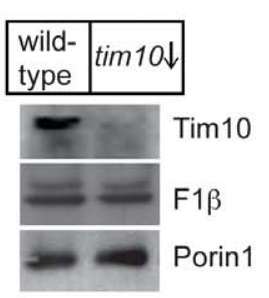

G.

\begin{tabular}{|c|c|c|c|c|c|c|}
\hline mitoplasting & \multirow{3}{*}{$\mathrm{L}$} & - & - & - & + & - \\
\hline \begin{tabular}{|l|} 
Triton-X-100 \\
\end{tabular} & & - & - & - & - & + \\
\hline Proteinase $\mathrm{K}$ & & - & + & + & + & + \\
\hline
\end{tabular}

Figure 4. LncP is transported to the mitochondrial inner membrane. (A) HeLa cells were transformed to express LncP-GFP or a control plasmid. The LncP-GFP cells were co-stained with tetramethylrhodamine methyl ester (TMRM) and viewed by confocal microscopy. The merge shows the mitochondrial localization of LnCP-GFP (B) Mitochondria $\left(50 \mu \mathrm{g}\right.$ protein) from wild-type yeast cells were incubated with $\left.{ }^{35} \mathrm{~S}\right]-$ labeled LncP. After the indicated time at $25^{\circ} \mathrm{C}$, mitochondria were isolated, treated with Proteinase $\mathrm{K}$ to degrade protein that had not been imported, and analyzed by SDSPAGE and fluorography. "T" represents non-Proteinase $\mathrm{K}$ treated control. "- $\Delta \psi_{\mathrm{m}}$ " indicates a sample where the mitochondria were pre-incubated with inhibitors and uncouplers to deplete the transmembrane potential (see Methods) (C) Mitochondria (100 $\mu \mathrm{g}$ protein) from wild-type cells were incubated with $\left[{ }^{35} \mathrm{~S}\right.$ ]-labeled LncP. After 20 minutes at $25^{\circ} \mathrm{C}$, mitochondria were isolated, extracted with $0.1 \mathrm{M} \mathrm{Na} 2 \mathrm{CO} 3$ and the membrane-containing pellet ("Pel") and extracted proteins in the supernatant ("S/N") analyzed by SDS-PAGE and fluorography and immunoblot against a known membrane embedded protein (Tim23) and a non-membrane embedded protein matrix localized protein $\left(F_{1} \beta\right)$. A sample of mitochondria prior to extraction and representing the total amount ("Tot.") is shown for comparison. The right-hand panel shows the percentage distribution of LncP in the pellet and supernatant fractions after 5 repeat experiments \pm standard error. (D) Mitochondria $(50 \mu \mathrm{g}$ protein) from wild-type and Tim 10 depleted (tim $10 \downarrow)$ yeast cells were resuspended in isotonic import buffer and incubated with ${ }^{35} \mathrm{~S}$ ]-labeled $\mathrm{LnCP}$ and $\mathrm{PiC}$. After the indicated time at $25^{\circ} \mathrm{C}$, mitochondria were isolated, solubilized in digitonin and analyzed by BN-PAGE and fluorography. Asterisk indicates bands formed by folded carrier proteins. The lower asterisk represents the folded monomer and the upper asterisk represents assembled carrier dimers (Stage $V$ ) (E) Mitochondria (50 $\mu \mathrm{g}$ protein) from wild-type yeast or from tim $10 \downarrow$ yeast depleted of Tim10 were incubated with $\left[{ }^{35} \mathrm{~S}\right.$-labeled $\mathrm{LnCP}$ or PiC. After the indicated time at $25^{\circ} \mathrm{C}$, the mitochondria were treated with Proteinase $\mathrm{K}$ and then analysed by SDS-PAGE and fluorography. "- $\Delta \psi_{\mathrm{m}}$ " indicates a sample where the mitochondria were pre-incubated with inhibitors and uncouplers to deplete the transmembrane potential (see Methods). (F) Control western blots with mitochondria isolated from wildtype and tim $10 \downarrow$ cells respectively showing that Tim10 has been selectively depleted. (G) The localization of LncP within mitochondria after import was determined using a sequential proteolysis assay. After import of $\left[{ }^{35} \mathrm{~S}\right]$-labeled LncP at $25^{\circ} \mathrm{C}$ for 20 minutes, mitochondria were treated with hypotonic buffer to induce mitoplasting, or Triton-X-100 to rupture both membranes and Proteinase $\mathrm{K}(50 \mu \mathrm{g} / \mathrm{mL}$ ) as indicated (see Methods). "L" is lysate only without mitochondria to show size of unimported protein. The control proteins, the inner membrane embedded protein (Tim23) and a non-membrane embedded protein matrix localized protein $\left(F_{1} \beta\right)$ were detected by immunoblot on the same membrane. doi:10.1371/journal.ppat.1002459.g004

The mechanism by which this recognition occurs is unknown but probably involves detection of a C-terminal Dot/Icm secretion signal. Here we removed the C-terminal amino acids PTRKR from LncP but found that this had no effect on LncP translocation.
Bioinformatic analysis of known Dot/Icm substrates has revealed a preference for short acidic or negatively charged amino acids in the C-terminal secretion signal [26,53]. Recently, a glutamate rich region (E Block) was associated with the translocation signal of 


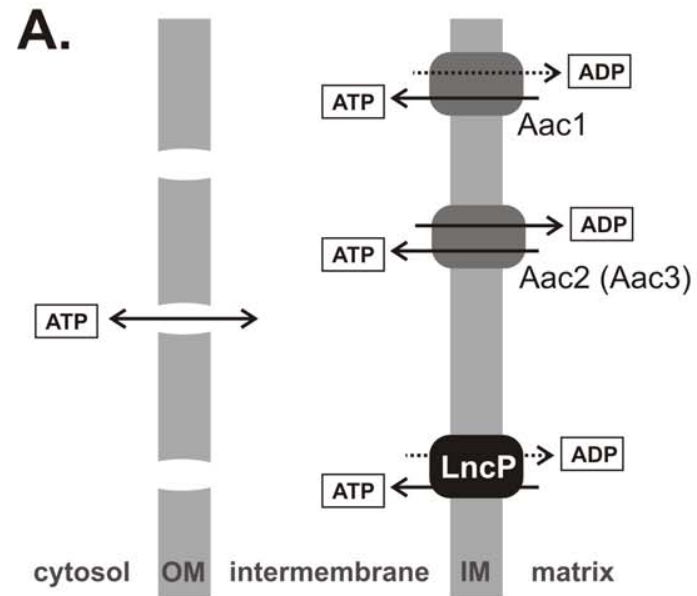

B.

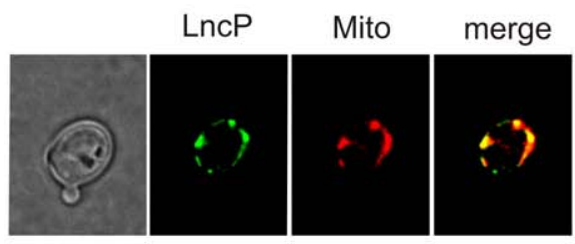

C.

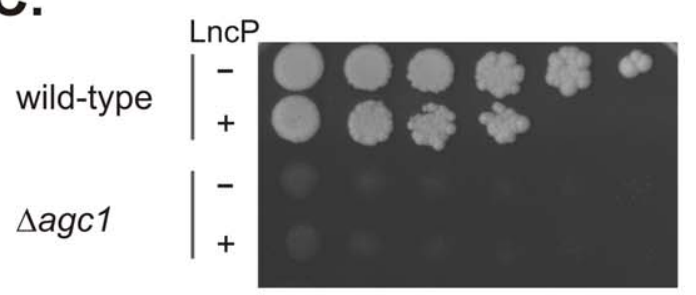

D.

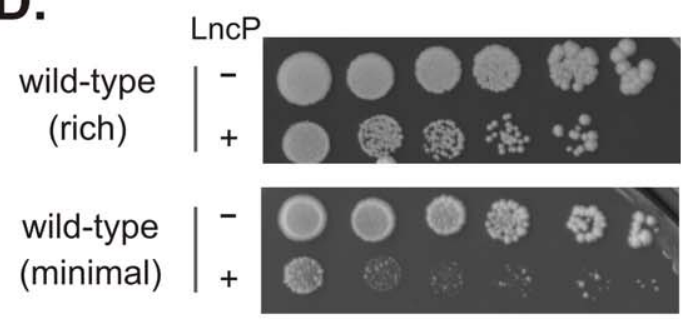

E.

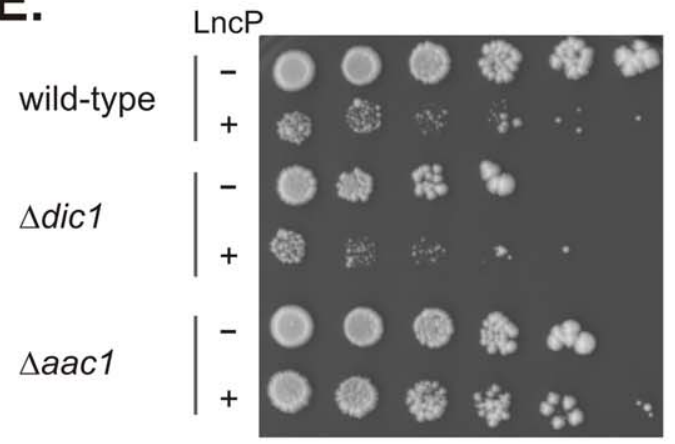

Figure 5. LncP generates a dominant negative phenotype, dependent on Aac1 ATP transport activity. (A) Yeast cells express three dominant carriers for adenine nucleotide transport: Aac1, Aac2 and Sal1 in the mitochondrial inner membrane (IM). Aac3 is an isoform expressed under anaerobic conditions [94]. The outer membrane (OM) of mitochondria is permeable to ATP due to the pores formed by VDAC. (B) Yeast cells transformed to express LncP-GFP were co-stained with MitoTracker Red and visualized by fluorescence microscopy. The merge shows the mitochondrial localization of LncP-GFP. (C) Yeast mutants, each lacking one member of the carrier protein family were transformed with either a plasmid encoding LncP (+) or the control (-) plasmid. The transformed cells were plated on selective medium and scored for growth using five-fold serial dilutions. As an example, the $\Delta a g c 1$ mutant is shown: Agc1 is an amino acid transporter which acts both as a glutamate uniporter and as an aspartate-glutamate exchanger; while viable on plates containing glycerol as a carbon source, the $\Delta a g c 1$ mutant cells form only microcolonies before arresting growth. Expression of LnCP does not support glutamate-aspartate transport and so does not rescue this phenotype. (D) Wild-type cells transformed with either a plasmid encoding LncP (+) or the control (-) plasmid were plated on YPD medium with glucose as a carbon source (rich) or SD semi-synthetic medium with glucose as a carbon source (minimal) and scored for growth using five-fold serial dilutions. The number of colonies represents cell viability. (E) Yeast mutants, each lacking a distinct carrier protein, were transformed with either the plasmid encoding LncP (+) or the control $(-)$ plasmid and scored for growth using five-fold serial dilutions. The $\Delta$ dic 1 mutant lacks the dicarboxylic acid transporter and is representative of carrier mutants in showing the same dominant-negative phenotype as wild-type cells. Only in the $\Delta a a c 1$ mutants is this phenotype suppressed. doi:10.1371/journal.ppat.1002459.g005

many Dot/Icm effectors [67]. The E Block motif was located in the $\mathrm{C}$-terminal 30 amino acids of the effectors. LncP also contains a putative E Block motif in the C-terminus that may contain the signal for translocation (Figure 1A). However, the motif is predicted to lie within the most distal transmembrane domain of the carrier protein and likely contributes to correct protein folding and function. Hence, further investigation of the LncP secretion signal will require careful mutational analysis by amino acid substitution rather than deletion to dissect the bona fide secretion signal from the transmembrane domain.

The mechanism by which hydrophobic membrane proteins such as LncP can be accommodated in the translocase channel and assisted on the host cytoplasmic side of the Legionellacontaining vacuole membrane without aggregating is unknown. When we analyzed the Dot/Icm effector repertoire of $L$. pneumophila 130b using two independent hidden Markov model approaches, HMMtop [68] and TMHMM v 2.0 [69], 71 effectors were predicted by both methods to have one or more transmembrane segments (Table S2). Thus the Dot/Icm T4SS has evolved to handle the export of proteins with significant hydrophobicity across at least three biological membranes.

Currently, mitochondrial localization of only one other Dot/ Icm effector, LegS2, has been reported, although the precise mitochondrial compartment was not described. LegS2 has sphingosine-1-phosphate lyase activity and it is not yet clear if mitochondrial targeting plays any role in effector function [27]. Here we found that $\mathrm{LncP}$ was also targeted to mitochondria during infection of eukaryotic cells with $L$. pneumophila and assembled into the mitochondrial inner membrane, where the effector appeared to act as a unidirectional nucleotide transporter. Mitochondrial import required the TIM9:10 chaperones and hence the TIM22 machinery, according to classical mitochondrial protein transport mechanisms.

In the yeast model system, expression of LncP led to a dominant-negative phenotype. Although not lethal, the expression of LncP greatly slowed growth, particularly growth on minimal media. This dominant-negative phenotype depended on the activity of the endogenous MCF protein, Aacl. Whereas the yeast MCFs Aac2 and Aac3 are classic ADP/ATP carriers that regenerate cytoplasmic ATP levels (because ATP export can only 

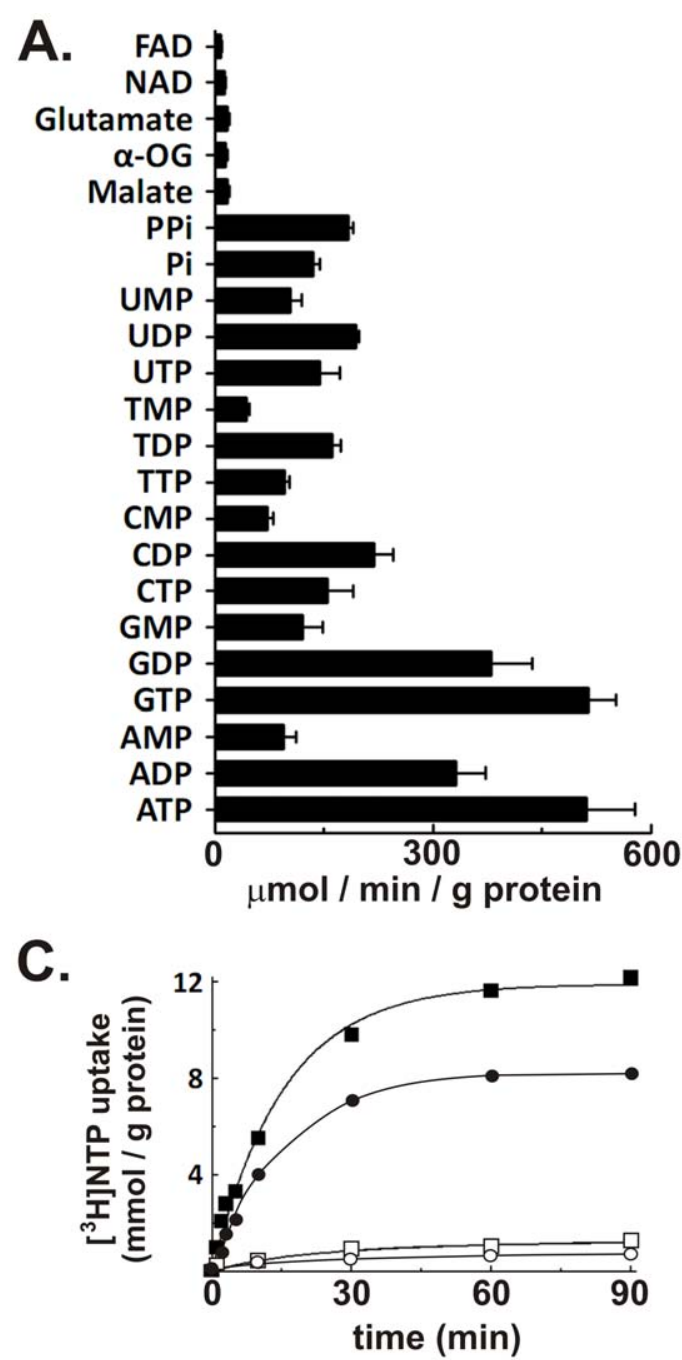

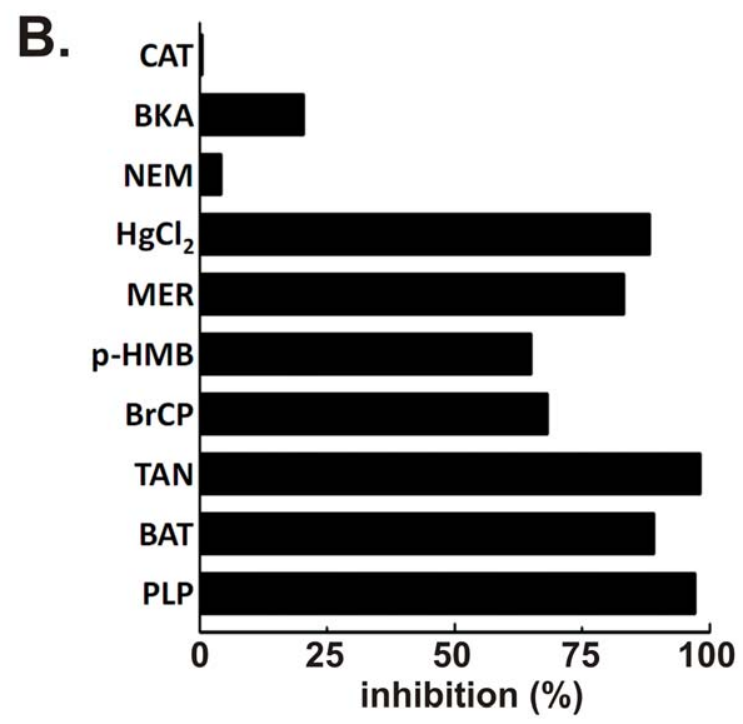

D.

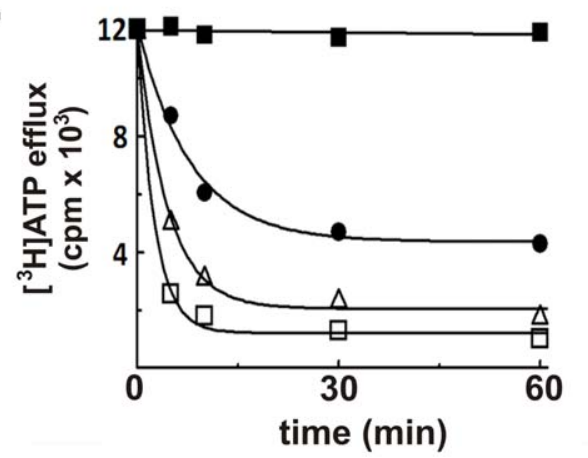

Figure 6. LncP is a nucleotide carrier with unique properties. (A) Liposomes reconstituted with LncP were preloaded internally with various substrates (concentration, $10 \mathrm{mM}$ ). Transport was started by the addition of $0.2 \mathrm{mM}\left[{ }^{3} \mathrm{H}\right]$ ATP and terminated after 2 min. Values are means \pm S.D. of at least three independent experiments. $\alpha$-OG, $\alpha$-oxoglutarate; Pi, phosphate; PPi, pyrophosphate. (B) Proteoliposomes were preloaded internally with $10 \mathrm{mM}$ ATP and transport was initiated by adding $0.2 \mathrm{mM}\left[{ }^{3} \mathrm{H}\right] \mathrm{ATP}$. The reaction time was $2 \mathrm{~min}$. Thiol reagents were added $2 \mathrm{~min}$ before the labeled substrate; the other inhibitors were added together with the labeled substrate. The final concentrations of the inhibitors were $20 \mathrm{mM}$ (PLP, pyridoxal5'-phosphate; BAT, bathophenanthroline), $0.2 \mathrm{mM}$ ( $p$-HMB, $p$-hydroxymercuribenzoate; MER, mersalyl), $1 \mathrm{mM}$ (NEM, $N$-ethylmaleimide), $0.2 \%$ (TAN, tannic acid), $0.2 \mathrm{mM}$ (BrCP, bromcresol purple), $25 \mu \mathrm{M}\left(\mathrm{HgCl}_{2}\right.$, mercuric chloride) and $10 \mu \mathrm{M}$ (BKA, bongkrekic acid; CAT, carboxyatractyloside). The extent of inhibition (\%) from representative experiments is given. (C) Uptake of $\left[{ }^{3} \mathrm{H}\right] \mathrm{ATP}(\boldsymbol{\square}, \square)$ and $\left[{ }^{3} \mathrm{H}\right] \mathrm{GTP}(\boldsymbol{\bullet}, \bigcirc)$ into liposomes reconstituted with LncP. $1 \mathrm{mM}\left[{ }^{3} \mathrm{H}\right]$ ATP or $\left[{ }^{3} \mathrm{H}\right]$ GTP was added to proteoliposomes containing $10 \mathrm{mM}$ ATP or GTP, respectively (exchange, filled shapes), or $10 \mathrm{mM}$ NaCl and no substrate (uniport, open shapes). Similar results were obtained in three independent experiments. (D) Efflux of $\left[{ }^{3} \mathrm{H}\right]$ ATP from LncP proteoliposomes. The internal substrate ( $2 \mathrm{mM}$ ATP) was labeled by carrier-mediated exchange equilibration. After removal of the external substrate by Sephadex G-75, the efflux of $\left[^{3} \mathrm{H}\right]$ ATP was started by adding buffer A alone (filled circles), $5 \mathrm{mM} \mathrm{ATP,} 20 \mathrm{mM}$ pyridoxal-5'-phosphate and $10 \mathrm{mM}$ bathophenanthroline in buffer A (filled squares), $5 \mathrm{mM}$ ATP in buffer A (open squares) or $5 \mathrm{mM}$ phosphate (open triangles). Similar results were obtained in three independent experiments.

doi:10.1371/journal.ppat.1002459.g006

be achieved with a concomitant import of ADP), a distinguishing feature of Aacl is its propensity to export ATP from the mitochondrial matrix [57]. Thus, the dominant-negative effect seen in yeast is likely a cellular consequence of an imbalance of ADP/ATP transport across the mitochondrial inner membrane.

We also observed ATP transport activity for LncP in reconstituted liposomes. The kinetic parameters of ATP transport by LncP were comparable to those of genuine ATP carriers. There are two classes of transporters for ATP in the mitochondrial inner membrane: the carboxyatractyloside-inhibitable ADP/ATP carriers (Aac) and the ATP-Mg/Pi carriers (in humans named APC and in yeast Sall). Studies in which the $V_{\max }$ of $A a c$ has been measured in reconstituted liposomes (either as ATP/ATP or $\mathrm{ADP} / \mathrm{ADP}$ exchange) using protein purified from mitochondria or after heterologous expression, obtained $\mathrm{V}_{\max }$ values ranging from 360 and $1300 \mathrm{mmol} / \mathrm{min} / \mathrm{g}$ protein [70-74]. Here we measured the $\mathrm{V}_{\max }$ of ATP transport in LncP-reconstituted liposomes (measured as ATP/ATP exchange) as $926 \mathrm{mmol} / \mathrm{min} / \mathrm{g}$ protein. This means that the ratio between the activity of LncP and the activity of genuine ADP/ATP carriers varied from 2.6 to 0.7 . The $\mathrm{K}_{\mathrm{m}}$ for ATP of genuine mitochondrial ADP/ATP carriers, measured in reconstituted liposomes, ranges between 9 and $120 \mu \mathrm{M}$, lower than the $\mathrm{K}_{\mathrm{m}}$ of $\operatorname{LncP}$ for ATP $(190 \mu \mathrm{M})$. However, the internal concentration of ATP in respiring mitochondria is 


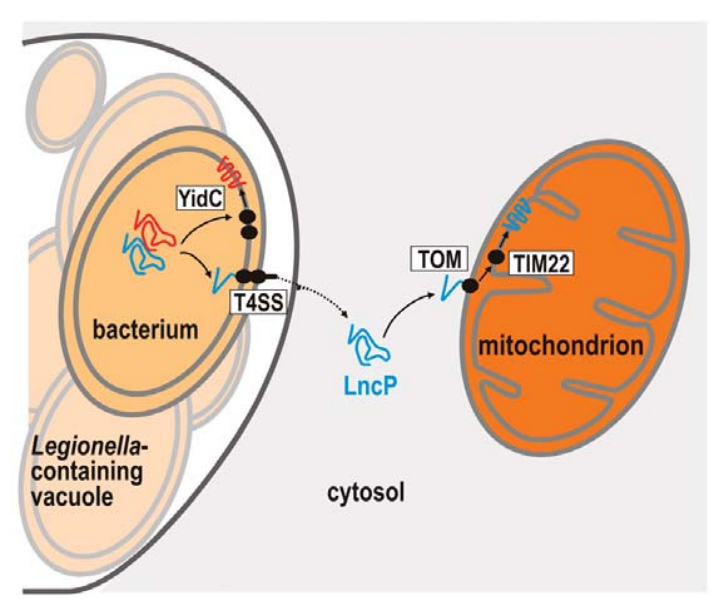

Figure 7. Transport of LncP across five membranes. Unlike regular bacterial inner membrane proteins with alpha-helical transmembrane segments (non-Dot/lcm effectors) (red), LncP (blue) avoids the YidC and SecYEG machinery in the bacterial inner membrane and is instead loaded into the T4SS for secretion across both the inner and outer bacterial membrane and across the vacuolar membrane. Similar to endogenous carrier proteins, LnCP is then presumably recognized by Hsp70 and Hsp90 chaperones in the host cell cytosol and delivered to the TOM complex via interactions with the Tom70 receptor. The protein is then translocated across the outer mitochondrial membrane and interacts with the Tim $9 / 10$ chaperones in the intermembrane space to be assembled into the mitochondrial inner membrane by the TIM22 complex. There, the transport activity of LncP would impact on nucleotide homeostasis between the mitochondrial matrix and host cell cytosol.

doi:10.1371/journal.ppat.1002459.g007

sufficiently high to saturate both $\mathrm{LncP}$ and Aac. To date there is no other data available about the kinetic parameters of carboxyatractyloside-sensitive ADP/ATP carriers either purified from mitochondria or after heterologous expression. For the ATP$\mathrm{Mg} / \mathrm{Pi}$ carrier, only the human orthologs encoded by the SLC25A23 and SLC25A24 genes have been reconstituted into liposomes [75]. The $\mathrm{V}_{\max }$ values of the ATP-Mg/Pi carriers (measured as ATP/ATP exchange) ranged from 65 to $523 \mathrm{mmol} /$ min/g protein, lower than the $\mathrm{V}_{\max }$ of $\mathrm{LncP}$. The $\mathrm{K}_{\mathrm{m}}$ values of human ATP-Mg/Pi carriers for ATP $(0.3 \mathrm{mM})$ are 1.5 -fold higher than the Km of LncP for ATP. In conclusion, the ATP transport activity of reconstituted $\mathrm{LncP}$ is at least as high as that of the known mitochondrial ATP transporters and is therefore compatible with the conclusion that LncP catalyzes ATP efflux from the mitochondria of infected cells.

Our reconstitution studies suggested LncP could evacuate ATP from the membrane lumen (matrix) by either uniport or an exchange reaction with substrates (e.g., phosphate). It is not yet clear how this assists $L$. pneumophila infection, however the high carriage of $\operatorname{lnc} P$ in strains of $L$. pneumophila and $L$. longbeachae suggests that control over mitochondrial adenine nucleotide levels favours Legionella replication and survival. While fundamental studies show that elevated levels of cytosolic ATP primes cells to respond to apoptosis-inducing stimuli [76,77], our preliminary experiments indicated that over-expression of LncP alone was insufficient to change the rate or extent of HeLa cell death induced by the exogenous trigger, staurosporine (Figure S2). Thus the contribution of LncP activity to $L$. pneumophila intracellular replication and persistence remains to be determined.

L. longbeachae and L. pneumophila share only some aspects of their life-cycle, and genome sequence analysis suggests that while these bacteria have a highly conserved Dot/Icm T4SS, they secrete quite different pools of effectors [46]. Despite this, L. longbeachae also harbors a strong homolog of LncP and two other putative MCF proteins. Further prokaryotic MCF sequences were found in another intracellular macrophage pathogen, $\mathcal{N}$. sennetsu, which causes an infectious mononucleosis-like disease called sennetsu ehrlichiosis [44]. The presence of these exclusively eukaryotic proteins in bacteria is curious and suggests that the genes encoding the MCF proteins were acquired at some stage by lateral gene transfer from a eukaryotic host. MCF proteins are found in almost all species of eukaryotes [78], including protists that support the growth of L. pneumophila. Based on previous analysis and our own HMM search we found MCF proteins in all of Acanthamoeba (unpublished), Dictyostelium discoideum [31,79] and Naegleria gruberi [80]. The association of bacterial MCF proteins with intracellular pathogens suggests the proteins could play similar roles in the pathogenesis of all these organisms. Further work on the biochemical function of the bacterial MCF members will aid our understanding of how bacteria modulate mitochondrial function during infection.

\section{Materials and Methods}

\section{Sequence Analysis}

The methodology for hidden Markov model analysis has been described previously [81]. A hidden Markov model tailored from 34 manually compiled mitochondrial carrier protein sequences was built and used to scan UniProt (Release 12.4, containing Swiss-Prot Release 54.4 and TrEMBL Release 37.4). The program HMMER 2.3.2 was used in all calculations [82], and the search results were extracted with programs prepared inhouse. Homology modeling of the mitochondria carrier protein was performed with SwissModel [83] using the structure of bovine ANT (PDB ID 2C3E) as the template [47]. Sequences were aligned using ClustalX [84] and further edited in BioEdit (http:/ / www.mbio.ncsu.edu/BioEdit/bioedit.html).

\section{Bacterial Strains and Culture Conditions}

L. pneumophila strain $130 \mathrm{~b}$ and derivatives were grown on buffered charcoal-yeast extract (BCYE) agar or in ACES [ $\mathcal{N}-(2-$ acetamido)-2-aminoethanesulfonic acid]-buffered yeast extract broth at $37^{\circ}$ C. E. coli strains were cultured aerobically in Luria broth (LB) or on LB agar. When required, antibiotics were used at the following final concentrations: ampicillin at $100 \mu \mathrm{g} / \mathrm{ml}$; kanamycin at $100 \mu \mathrm{g} / \mathrm{ml}$ for E. coli, at $25 \mu \mathrm{g} / \mathrm{ml}$ for L. pneumophila; chloramphenicol at $12.5 \mu \mathrm{g} / \mathrm{ml}$ for $E$. coli, at $6 \mu \mathrm{g} / \mathrm{ml}$ for $L$. pneumophila.

\section{Yeast Culture and Cell Fractionation}

Saccharomyces cerevisiae strain W303a was grown in rich medium or selective medium as previously described [85]. For ectopic expression of LncP in yeast, the complete $\operatorname{lnc} P$ open reading frame was amplified by PCR from L. pneumophila $130 \mathrm{~b}$ genomic DNA and cloned into p425MET25 and p416MET25 for complementation or GFP-LncP localization respectively. The individual carrier deletionmutants (in a BY4741 background) were purchased from Open Biosystems. For the preparation of mitochondria yeast cultures were grown in rich medium containing lactate as a carbon source (YPlac media) at $25^{\circ} \mathrm{C}$. Mitochondria were isolated by differential centrifugation as described previously $[85,86]$. For the growth assays the cells were grown to a mid-logarithmic phase in a complete medium, diluted to $\mathrm{OD}_{600}=0.2$, spotted in a series of five-fold dilutions on the plates and incubated at $30^{\circ} \mathrm{C}$ for $3-6$ days. 


\section{Isolation of Yeast Mitochondria}

For the isolation of wildtype and Tim10 depleted mitochondria

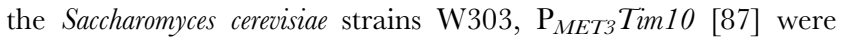
grown in synthetic glucose media $[0.67 \%(\mathrm{w} / \mathrm{v})$ yeast nitrogen, $2 \%$ $(\mathrm{w} / \mathrm{v})$ glucose, $0.01 \%(\mathrm{w} / \mathrm{v})$ leucine, tryptophan, uracil, adenine and histidine at $30^{\circ} \mathrm{C}$ for 10 hours as a pre-culture. The preculture was diluted to $A_{600 \mathrm{~nm}}=0.2 \mathrm{units} / \mathrm{mL}$ in media supplemented with $0.2 \mathrm{mM}$ methionine then grown for 2 days to reach $A_{600 \mathrm{~nm}}=1.0$ before harvesting and mitochondrial isolation by previously described methods [86].

\section{Synthesis of $\left[{ }^{35} \mathrm{~S}\right]$-labeled LncP}

DNA encoding LncP was amplified and cloned into pSP73 (Promega) from genomic DNA isolated Legionella pneumophila (strain 130b). The oligonucleotides LncP-FW BamHI (GGGGGGATCCATGAAAGACAAAACAATA), and LncP-REV XhoI (GATCC TGGAGCTACGTGTTCGTTGTTGG) were used to amplify full length LncP DNA In vitro transcription was carried out as previously described [88]. Rabbit reticulocyte lysate was purchased from Promega and in vitro translation reactions were carried out for 30-60 minutes in the presence of $\left[{ }^{35} \mathrm{~S}\right]-$ methionine/ cysteine (MP Biomedicals) [88].

\section{In vitro Import Reactions}

$\left[{ }^{35} \mathrm{~S}\right]$-Methionine/cysteine-labeled LncP or PiC were synthesized in vitro and were incubated with mitochondria ( $50 \mu \mathrm{g}$ per lane) for the indicated time periods at $25^{\circ} \mathrm{C}$ in import buffer $(0.6 \mathrm{M}$ sorbitol, $50 \mathrm{mM}$ Hepes (pH 7.4), $2 \mathrm{mM} \mathrm{KPi}(\mathrm{pH}$ 7.4), $25 \mathrm{mM} \mathrm{KCl}, 10 \mathrm{mM}$ $\mathrm{MgCl}_{2}, 0.5 \mathrm{mM}$ EDTA, $1 \mathrm{mM}$ dithiothreitol, $4 \mathrm{mM} \mathrm{ATP}$, and $2 \mathrm{mM} \mathrm{NADH})$. Samples were treated with Proteinase K $(40 \mu \mathrm{g} /$ $\mathrm{mL}$ ) in import buffer for 15 minutes on ice to remove un-imported material before addition of protease inhibitor ( $1 \mathrm{mM}$ PMSF). The mitochondria were re-isolated by centrifugation at $10,000 \mathrm{~g}$ and this was followed by either protein separation under denaturing gel electrophoresis (SDS) or protein complexes separated by Blue Native electrophoresis [89]. For Proteinase K shaving or mitochondrial membrane potential dissipation conditions, mitochondria were treated with $40 \mu \mathrm{g} / \mathrm{ml}$ Proteinase $\mathrm{K}$ or AVO mix $(8 \mu \mathrm{M}$ antimycin A, $1 \mu \mathrm{M}$ valinomycin, and $20 \mu \mathrm{M}$ oligomycin) respectively. For preparation of mitoplasts (mitochondria with ruptured outer mitochondrial membrane), post-import mitochondria were subjected to osmotic shock by resuspension in $20 \mathrm{mM}$ Hepes/ $\mathrm{KOH}, \mathrm{pH} 7.4$ with and without Proteinase $\mathrm{K}$ where indicated.

\section{Sodium Carbonate Extractions}

After the completion of in vitro import reactions for 8 minutes at $25^{\circ} \mathrm{C}$, mitochondria were re-isolated by centrifugation at $10,000 \mathrm{~g}$ and resuspended in $200 \mu \mathrm{L}$ of $100 \mathrm{mM}$ sodium carbonate which was adjusted to $\mathrm{pH} 11.5$ and left on ice for 30 minutes with gentle mixing every 5 to 10 minutes. A membrane pellet was then separated from a supernatant by ultra-centrifugation at $100,000 \mathrm{~g}$ for 30 minutes at $4^{\circ} \mathrm{C}$. The pellet was resuspended in $200 \mu \mathrm{L}$ of $100 \mathrm{mM}$ sodium carbonate and both the pellet and supernatant were then subjected to Trichloroacetic acid precipitation. Each experiment was conducted in duplicate with one set of pellet and supernatant samples recombined to make the "total" sample. This was repeated 5 times in order to assess statistical significance. LncP protein level was quantified by densitometry of phosphorimages using the Image Quant software.

\section{Reconstitution of LncP into Liposomes and Transport Measurements}

Expression of recombinant LncP is detailed in the supporting methods (Protocol S1). The recombinant, purified LncP was reconstituted into liposomes by cyclic removal of the detergent with a hydrophobic column of Amberlite beads (Fluka) [61]. The composition of the initial mixture used for reconstitution was $35 \mu \mathrm{l}$ of purified LncP (15 $\mu \mathrm{g}$ of protein), $70 \mu \mathrm{l}$ of $10 \%$ Triton X-114, $100 \mu \mathrm{l}$ of $10 \%$ phospholipids in the form of sonicated liposomes, $10 \mathrm{mM}$ ATP (except where otherwise indicated), $10 \mathrm{mM}$ PIPES (pH 7.0), $0.42 \mathrm{mg}$ of the mitochondrial lipid cardiolipin (Sigma) and water to a final volume of $700 \mu \mathrm{l}$. After vortexing, this mixture was recycled 13 times through the Amberlite column $(3.5 \times 0.5 \mathrm{~cm})$ pre-equilibrated with a buffer containing $10 \mathrm{mM}$ PIPES pH 7.0. All steps were performed at $4^{\circ} \mathrm{C}$, except for the passages through Amberlite, which were carried out at room temperature.

External substrate was removed from proteoliposomes on Sephadex G-75 columns pre-equilibrated with $50 \mathrm{mM} \mathrm{NaCl}$ and $10 \mathrm{mM}$ PIPES at pH 7.0 (buffer A) and $4^{\circ} \mathrm{C}$. The eluted proteoliposomes were distributed in reaction vessels and used for transport measurements by the inhibitor-stop method [61]. Transport at $25^{\circ} \mathrm{C}$ was started by adding $\left[{ }^{3} \mathrm{H}\right]$ ATP (Perkin Elmer) or $\left[{ }^{3} \mathrm{H}\right] \mathrm{GTP}$ (American Radiolabeled Chemicals) to proteoliposomes and terminated by addition of $20 \mathrm{mM}$ pyridoxal- $5^{\prime}-$ phosphate and $20 \mathrm{mM}$ bathophenanthroline. In controls, the inhibitors were added at the beginning together with the radioactive substrate. Finally, the external radioactivity was removed from each sample of proteoliposomes by a Sephadex G-75 column; the proteoliposomes were eluted with buffer A and their radioactivity was measured. The experimental values were corrected by subtracting control values. The initial transport rate was calculated from the radioactivity taken up by proteoliposomes after $2 \mathrm{~min}$ (in the initial linear range of substrate uptake). For efflux measurements, proteoliposomes containing $2 \mathrm{mM}$ ATP or GTP were labeled with $10 \mu \mathrm{M}\left[{ }^{3} \mathrm{H}\right] \mathrm{ATP}$ or $\left[{ }^{3} \mathrm{H}\right] \mathrm{GTP}$, respectively, by carrier-mediated exchange equilibration [61]. After $50 \mathrm{~min}$, the external radioactivity was removed by passing the proteoliposomes through Sephadex G-75 pre-equilibrated with buffer A. Efflux was started by adding unlabeled external substrate or buffer A alone to aliquots of proteoliposomes and terminated by adding the inhibitors indicated above.

\section{Disruption of LncP in L. pneumophila 130b}

An insertional mutation in $\mathrm{LncP}$ was created via homologous recombination. A $\sim 1 \mathrm{~kb}$ fragment encompassing LncP was amplified by PCR from L. pneumophila 130b genomic DNA using the oligonucleotide primers, $5^{\prime}$ - caacggatcctatttcatttgtagtccttg $-3^{\prime}$ and $5^{\prime}$ - tcctgtcgacctgaaatatttcatggaaac $-3^{\prime}$. The resulting product was cloned into the BamHI and SalI sites of pPCRScript and a kanamycin resistance gene from Tn5 was introduced into the native $P s t \mathrm{I}$ site of $\mathrm{LncP}$. The construct was introduced into $L$. pneumophila $130 \mathrm{~b}$ via natural transformation, as described previously [90]. Kanamycin resistant clones were assessed by PCR analysis and ampicillin sensitivity to detect replacement of $\operatorname{lnc} P$ with $l n c P:: k m$ and the loss of pCR-Script. Two independent $L$. pneumophila $\operatorname{lncP}:: k m$ clones, LncP-3 and LncP-4, were chosen for further analysis in host cell replication assays.

\section{Macrophage and HeLa Cell Infection and Anti-HA Immunofluorescence}

The human monocytic cell line, THP-1 was maintained in RPMI 1640 supplemented with $10 \%$ fetal bovine serum in 5\% $\mathrm{CO}_{2}$ at $37^{\circ} \mathrm{C}$. The cells were prepared for infection with stationary-phase L. pneumophila as previously described [91]. THP-1 cells were infected at a multiplicity of infection (MOI) of 5 cells for $2 \mathrm{~h}$ in $5 \% \mathrm{CO}_{2}$ at $37^{\circ} \mathrm{C}$. Cells were then treated with $100 \mu \mathrm{g} / \mathrm{ml}$ gentamicin for $1 \mathrm{~h}$ to kill extracellular bacteria and washed with PBS before being lysed with $0.01 \%$ digitonin. 
Serial dilutions of the inoculum and bacteria recovered from lysed cells were plated on BCYE agar and results were expressed as the percentage of the inoculum that resisted killing by gentamicin (mean \pm standard deviation of at least 3 independent experiments).

Immortalized macrophages from wild type C57BL/6 mice [92] were seeded at $2 \times 10^{5}$ per coverslip $16 \mathrm{~h}$ prior infection. The B6 macrophages were a gift from Dr Ashley Mansell (Monash Institute of Medical Research). Cells were maintained in DMEM supplemented with 10\% FCS, 2 mM glutamine, $100 \mathrm{U}$ penicillin/ $\mathrm{ml}$ and $100 \mu \mathrm{g}$ streptomycin/ml. Immediately prior to infection, macrophages were washed and the medium replaced with DMEM supplemented with $1 \mathrm{mM}$ IPTG and lacking antibiotics. Macrophages were infected for $30 \mathrm{~min}, 1 \mathrm{~h}, 2 \mathrm{~h}, 3 \mathrm{~h}$ or $5 \mathrm{~h}$ with derivatives of $L$. pneumophila $130 \mathrm{~b}$ at a multiplicity of infection of 50. Bacterial strains for infection were grown overnight in ACES broth supplemented with antibiotics where appropriate and $1 \mathrm{mM}$ IPTG. HeLa cells were infected using an identical protocol. Following the infection period, cells were washed once with fresh tissue culture medium and incubated with $500 \mathrm{nM}$ Mitotracker ${ }^{\circledR}$ Red FM (Invitrogen) for $30 \mathrm{~min}$ at $37^{\circ} \mathrm{C}$ and $5 \% \mathrm{CO}_{2}$. Labelled cells were then fixed in $4 \%$ paraformaldehyde-PBS for $20 \mathrm{~min}$ and permeabilized with $0.1 \%$ TritonX-100-PBS for $20 \mathrm{~min}$. Cells were incubated for $60 \mathrm{~min}$ in staining solution containing $0.2 \% \mathrm{BSA}$, 1:50 dilution of anti-HA.11 monoclonal antibody (Covance) and 1:75 dilution of rabbit raised anti-Legionella pneumophila antibody (Acris). The bound primary antibodies were detected using 1:1000 dilution of Alexa Fluor 405-conjugated anti-rabbit antibody and Alexa Fluor 488-conjugated anti-mouse antibody (Invitrogen) respectively. Coverslips were mounted onto glass slides with Dako Fluorescent Mounting Medium (Dako). Immunofluorescence images were acquired using a confocal laser scanning microscope (Leica TCS SP2 confocal imaging system) with a 100x/1.4 NA HCX PL APO CS oil immersion objective.

\section{Cya-LncP and 4HA Gene Fusions and Intracellular cAMP Assays}

Adenylate cyclase (Cya) fusions with RalF and LncP were generated as described previously [51]. Details are provided in the supporting methods (Protocol S1). Hemagluttinin (HA) fusions with LncP were generated as described in the supporting methods (Protocol S1).

\section{Infection of $A$. castellanii with $L$. pneumophila}

A. castellanii ATCG 50739 was cultured in PYG 712 medium at $20^{\circ} \mathrm{C}$ for $72 \mathrm{~h}$ prior to harvesting for L. pneumophila infection. A. castellanii cells were washed once with A.c. buffer $(0.1 \%$ trisodium citrate, $0.4 \mathrm{mM} \mathrm{CaCl} 2,2,5 \mathrm{mM} \mathrm{KH}_{2} \mathrm{PO}_{4}, 4 \mathrm{mM} \mathrm{MgSO}_{4}$, $2.5 \mathrm{mM} \mathrm{Na} \mathrm{HPO}_{4}, 0.005 \mathrm{mM}$ ferric pyrophosphate) and seeded into 24-well tissue culture trays (Sarstedt, Leicestershire, United Kingdom) at a density of $10^{5}$ cells/well. Stationary-phase $L$. pneumophila was added at an MOI of 0.01 and incubated at $37^{\circ} \mathrm{C}$. At set time points, entire co-culture volumes were collected and plated onto BCYE agar to count colony-forming units of $L$. pneumophila.

\section{LncP Purification}

Proteins were analyzed by SDS-PAGE or by Blue Native (BN)PAGE (Figure S3) as previously described [85]. N-terminal sequencing was carried out as described previously [93]. Purified LncP was quantified by laser densitometry of stained samples, using carbonic anhydrase as the protein standard [93]. Protein incorporation into liposomes was measured as described [93] and varied between $20-30 \%$ of the protein added to the reconstitution mixture.

\section{Supporting Information}

Figure S1 Localization of 4HA-LncP in macrophages and HeLa cells. (A) Macrophages were infected with $L$. pneumophila (either wild type $130 \mathrm{~b}$ or the $\Delta d o t A$ mutant) expressing 4HA-LncP. Bacteria were visualized using anti-Legionella antibodies (blue) 4HA-LncP was visualized with antibodies to HA (green). Prior to fixation, cell were stained with MitoTracker Red. Cells were viewed by confocal microscopy under a $100 \times$ objective. The merge shows the mitochondrial localization of 4HA-LncP. White scale bars represent $10 \mu \mathrm{m}$ (B) HeLa cells infected with $L$. pneumophila (either wild type $130 \mathrm{~b}$ or the $\Delta d o t A$ mutant) expressing 4HA-LncP were analyzed as above.

(TIF)

Figure S2 LncP is targeted to mitochondria, but does not impact on apoptosis induced by staurosporine treatment. (A) LncP-EGFP was expressed in HeLa cells. Cells were immunostained with antibodies against GFP (green) and active caspase-3 (red). Hoechst 33342 was used as a counterstain to indicate nucleus (blue). The panel at the right shows the cells treated with staurosporine for 5-6 hours. The left panel shows the cells without staurosporine treatment. Scale bar: $10 \mu \mathrm{m}$. The Table documents the analysis by cell counting. Total cells were counted based on nucleus staining. LncP-EGFP expressing cells were counted based on green color while cells with active caspase3 were counted based on red color. (B) HeLa cells were transfected with LncP-EGFP (green) and then stained with tetramethylrhodamine methyl ester (TMRM) (red). The right panel shows the cells treated with vehicle DMSO for 5 hours while the left panel is the cells without treatment. Scale bar: $50 \mu \mathrm{m}$ (C) HeLa cells transfected with LncP-EGFP (green) were stained with TMRM (red) and then treated with staurosporine for up to 3 hours. The panel at the right shows fluorescence images while the left panel shows bright field images. Scale bar: $50 \mu \mathrm{m}$. (TIF)

Figure S3 Recombinant expression and purification of LncP. Proteins were separated by SDS-PAGE and stained with Coomassie Blue. Markers in left-hand column (bovine serum albumin, carbonic anhydrase, and cytochrome c); lanes 1-4, Escherichia coli C0214 (DE3) containing the expression vector without (lanes 1 and 3) and with (lanes 2 and 4) the coding sequence of LncP. Samples were taken at the time of induction (lanes 1 and 2) and $5 \mathrm{~h}$ later (lanes 3 and 4). The same number of bacteria was analyzed in each sample. Lane 5, purified LncP protein $(5 \mu \mathrm{g})$ purified from $E$. coli shown in lane 4 . The identity of the purified protein was confirmed by $\mathrm{N}$-terminal sequencing. Approximately $55 \mathrm{mg}$ of purified protein per liter of culture were obtained.

(TIF)

\section{Protocol S1 Supporting methods.} (DOC)

Table S1 Prevalence of $\operatorname{lncP}$ among strains of $L$. pneumophila. A range of L. pneumophila strains were tested for carriage of $\operatorname{lnc} P$ by Southern hybridisation as described previously [90]. A digoxigenin (DIG)-labelled probe was generated by PCR amplification according to the manufacturer's instructions (Roche) with the primer pair $5^{\prime}$ - caacggatcctatttcatttgtagtccettg $-3^{\prime}$ and $5^{\prime}-$ tcctgtcgacctgaaatatttcatggaaac $-3^{\prime}$ using L. pneumophila $130 \mathrm{~b}$ genomic DNA as a template [45].

(DOC) 
Table S2 Predicted membrane proteins in the $L$. pneumophila Dot/Icm effector repertoire. Two hundred strain Philadelphia were identified as effector proteins in a recent high-throughput study [13]. Here the protein sequences of these effectors as well effectors unique to L. pneumophila strain 130b were analyzed with HMMtop [68] and TMHMM v 2.0 [69] to predict transmembrane segments. The two predictors have independent means of assessing hydrophobicity and other characteristics of alpha-helical transmembrane segments, yet concordant predictions are seen for most proteins.

(DOC) and seventy-five proteins encoded in the genome of L. pneumophila

\section{Acknowledgments}

We thank Vladamir Likić, Ana Traven and Chaille Webb for expert advice, and Victoria Hewitt and members of the Lithgow and Hartland labs for critical comments on the manuscript. We are grateful to Patrice Riedmaier for immunoblot analysis of 4HA-LncP, and to Craig Roy for the gift of pEC34 (pCya). The authors acknowledge the facilities, scientific and technical assistance of Monash Micro Imaging, Monash University, Victoria, Australia.

\section{Author Contributions}

Conceived and designed the experiments: PD MA JT JHJ CMM EB FP KG GG ELH TL. Performed the experiments: PD MA SFL RS JT JHJ CMM EB GG. Analyzed the data: PD SB TN JT JHJ CMM EB FP KG GG ELH TL. Contributed reagents/materials/analysis tools: AM GF. Wrote the paper: PD ELH TL FP.

\section{References}

1. Horwitz MA (1983) The Legionnaires' disease bacterium (Legionella pneumophila) inhibits phagosome-lysosome fusion in human monocytes. J Exp Med 158: 2108-2126.

2. Horwitz MA, Silverstein SC (1980) Legionnaires' disease bacterium (Legionella pneumophila) multiples intracellularly in human monocytes. J Clin Invest 66: $441-450$.

3. Kagan JC, Roy CR (2002) Legionella phagosomes intercept vesicular traffic from endoplasmic reticulum exit sites. Nat Cell Biol 4: 945-954.

4. Horwitz MA (1983) Formation of a novel phagosome by the Legionnaires' disease bacterium (Legionella pneumophila) in human monocytes. J Exp Med 158: 1319-1331.

5. Tilney LG, Harb OS, Connelly PS, Robinson CG, Roy CR (2001) How the parasitic bacterium Legionella pneumophila modifies its phagosome and transforms it into rough ER: implications for conversion of plasma membrane to the ER membrane. J Cell Sci 114: 4637-4650.

6. Isberg RR, O'Connor TJ, Heidtman M (2009) The Legionella pneumophila replication vacuole: making a cosy niche inside host cells. Nat Rev Microbiol 7: 13-24.

7. Roy CR, Tilney LG (2002) The road less traveled: transport of Legionella to the endoplasmic reticulum. J Cell Biol 158: 415-419.

8. Urwyler S, Nyfeler Y, Ragaz C, Lee H, Mueller LN, et al. (2009) Proteome analysis of Legionella vacuoles purified by magnetic immunoseparation reveals secretory and endosomal GTPases. Traffic 10: 76-87.

9. Dorer MS, Kirton D, Bader JS, Isberg RR (2006) RNA interference analysis of Legionella in Drosophila cells: exploitation of early secretory apparatus dynamics. PLoS Pathog 2: e34.

10. Segal G, Purcell M, Shuman HA (1998) Host cell killing and bacterial conjugation require overlapping sets of genes within a $22-\mathrm{kb}$ region of the Legionella pneumophila genome. Proc Natl Acad Sci U S A 95: 1669-1674.

11. Segal G, Shuman HA (1997) Characterization of a new region required for macrophage killing by Legionella pneumophila. Infect Immun 65: 5057-5066.

12. Vogel JP, Andrews HL, Wong SK, Isberg RR (1998) Conjugative transfer by the virulence system of Legionella pneumophila. Science 279: 873-876.

13. Zhu W, Banga S, Tan Y, Zheng C, Stephenson R, et al. (2011) Comprehensive identification of protein substrates of the Dot/Icm type IV transporter of Legionella pneumophila. PLoS One 6: e17638.

14. Hubber A, Roy CR (2010) Modulation of host cell function by Legionella pneumophila type IV effectors. Annu Rev Cell Dev Biol 26: 261-283.

15. Franco IS, Shuman HA, Charpentier X (2009) The perplexing functions and surprising origins of Legionella pneumophila type IV secretion effectors. Cell Microbiol 11: 1435-1443.

16. Newton HJ, Ang DK, van Driel IR, Hartland EL (2010) Molecular pathogenesis of infections caused by Legionella pneumophila. Clin Microbiol Rev 23: 274-298.

17. Weber SS, Ragaz C, Hilbi H (2009) Pathogen trafficking pathways and host phosphoinositide metabolism. Mol Microbiol 71: 1341-1352.

18. Machner MP, Isberg RR (2007) A bifunctional bacterial protein links GDI displacement to Rabl activation. Science 318: 974-977.

19. Shohdy N, Efe JA, Emr SD, Shuman HA (2005) Pathogen effector protein screening in yeast identifies Legionella factors that interfere with membrane trafficking. Proc Natl Acad Sci U S A 102: 4866-4871.

20. Ingmundson A, Delprato A, Lambright DG, Roy CR (2007) Legionella pneumophila proteins that regulate Rabl membrane cycling. Nature 450: 365-369.

21. Weber SS, Ragaz C, Reus K, Nyfeler Y, Hilbi H (2006) Legionella pneumophila exploits $\mathrm{PI}(4) \mathrm{P}$ to anchor secreted effector proteins to the replicative vacuole. PLoS Pathog 2: e46.

22. Cazalet C, Rusniok C, Bruggemann H, Zidane N, Magnier A, et al. (2004) Evidence in the Legionella pneumophila genome for exploitation of host cell functions and high genome plasticity. Nature Genet 36: 1165-1173.

23. Pan X, Luhrmann A, Satoh A, Laskowski-Arce MA, Roy CR (2008) Ankyrin repeat proteins comprise a diverse family of bacterial type IV effectors. Science 320: $1651-1654$
24. Price CT, Al-Quadan T, Santic M, Jones SC, Abu Kwaik Y (2010) Exploitation of conserved eukaryotic host cell farnesylation machinery by an F-box effector of Legionella pneumophila. J Exp Med 207: 1713-1726.

25. Lomma M, Dervins-Ravault D, Rolando M, Nora T, Newton HJ, et al. (2010) The Legionella pneumophila F-box protein Lpp2082 (AnkB) modulates ubiquitination of the host protein parvin $\mathrm{B}$ and promotes intracellular replication. Cell Microbiol 12: 1272-1291.

26. Kubori T, Hyakutake A, Nagai H (2008) Legionella translocates an E3 ubiquitin ligase that has multiple U-boxes with distinct functions. Mol Microbiol 67: 1307-1319.

27. Degtyar E, Zusman T, Ehrlich M, Segal G (2009) A Legionella effector acquired from protozoa is involved in sphingolipids metabolism and is targeted to the host cell mitochondria. Cell Microbiol 11: 1219-1235.

28. Alcock F, Clements A, Webb C, Lithgow T (2010) Evolution. Tinkering inside the organelle. Science 327: 649-650.

29. Jarmuszkiewicz W, Czarna M, Swida A, Behrendt M (2004) Uncoupling Proteins in Amoeboid Eukaryotes, Acanthamoeba castellanii, and Dictyostelium discoideum. Toxicol Mech Methods 14: 3-6.

30. Chan KW, Slotboom DJ, Cox S, Embley TM, Fabre O, et al. (2005) A novel ADP/ATP transporter in the mitosome of the microaerophilic human parasite Entamoeba histolytica. Curr Biol 15: 737-742.

31. Satre M, Mattei S, Aubry L, Gaudet P, Pelosi L, et al. (2007) Mitochondrial carrier family: repertoire and peculiarities of the cellular slime mould Dictyostelium discoideum. Biochimie 89: 1058-1069.

32. Dolezal P, Dagley MJ, Kono M, Wolynec P, Likic VA, et al. (2010) The essentials of protein import in the degenerate mitochondrion of Entamoeba histolytica. PLoS Pathog 6: e1000812.

33. Young JC, Hoogenraad NJ, Hartl FU (2003) Molecular chaperones Hsp90 and Hsp70 deliver preproteins to the mitochondrial import receptor Tom70. Cell 112: 41-50.

34. Koehler CM (2004) New developments in mitochondrial assembly. Annu Rev Cell Dev Biol 20: 309-335.

35. Gabriel K, Pfanner N (2007) The mitochondrial machinery for import of precursor proteins. Methods Mol Biol 390: 99-117.

36. Neupert W, Herrmann JM (2007) Translocation of proteins into mitochondria. Annu Rev Biochem 76: 723-749.

37. Chacinska A, Koehler CM, Milenkovic D, Lithgow T, Pfanner N (2009) Importing mitochondrial proteins: machineries and mechanisms. Cell 138: 628-644.

38. Picault N, Hodges M, Palmieri L, Palmieri F (2004) The growing family of mitochondrial carriers in Arabidopsis. Trends Plant Sci 9: 138-146.

39. Palmieri F, Pierri CL (2010) Mitochondrial metabolite transport. Essays Biochem 47: 37-52.

40. Palmieri F (2004) The mitochondrial transporter family (SLC25): physiological and pathological implications. Pflugers Arch 447: 689-709.

41. Palmieri F, Pierri CL, De Grassi A, Nunes-Nesi A, Fernie AR (2011) Evolution, structure and function of mitochondrial carriers: a review with new insights. Plant J 66: 161-181.

42. Palmieri F, Pierri CL (2010) Structure and function of mitochondrial carriers role of the transmembrane helix $\mathrm{P}$ and $\mathrm{G}$ residues in the gating and transport mechanism. FEBS Lett 584: 1931-1939.

43. Rikihisa Y (2003) Mechanisms to create a safe haven by members of the family Anaplasmataceae. Ann N Y Acad Sci 990: 548-555.

44. Walker DH (2009) Sennetsu neorickettsiosis: a potentially prevalent, treatable, acutely incapacitating tropical infectious disease. Am J Trop Med Hyg 81: 187-188.

45. Schroeder GN, Petty NK, Mousnier A, Harding CR, Vogrin AJ, et al. (2010) Legionella pneumophila strain $130 \mathrm{~b}$ possesses a unique combination of type IV secretion systems and novel Dot/Icm secretion system effector proteins. J Bacteriol 192: 6001-6016. 
46. Cazalet C, Gomez-Valero L, Rusniok C, Lomma M, Dervins-Ravault D, et al. (2010) Analysis of the Legionella longbeachae genome and transcriptome uncovers unique strategies to cause Legionnaires' disease. PLoS Genet 6: e1000851.

47. Pebay-Peyroula E, Dahout-Gonzalez C, Kahn R, Trezeguet V, Lauquin GJ, et al. (2003) Structure of mitochondrial ADP/ATP carrier in complex with carboxyatractyloside. Nature 426: 39-44.

48. Greub G, Raoult D (2003) History of the ADP/ATP-translocase-encoding gene, a parasitism gene transferred from a Chlamydiales ancestor to plants 1 billion years ago. App Environ Microbiol 69: 5530-5535.

49. Schmitz-Esser S, Linka N, Collingro A, Beier CL, Neuhaus HE, et al. (2004) ATP/ADP translocases: a common feature of obligate intracellular amoebal symbionts related to Chlamydiae and Rickettsiae. J Bacteriol 186: 683-691.

50. Trentmann O, Horn M, van Scheltinga AC, Neuhaus HE, Haferkamp I (2007) Enlightening energy parasitism by analysis of an ATP/ADP transporter from chlamydiae. PLoS Biol 5: e231.

51. Cambronne ED, Roy CR (2007) The Legionella pneumophila IcmSW complex interacts with multiple Dot/Icm effectors to facilitate type IV translocation. PLoS Pathog 3: e188.

52. Nagai H, Cambronne ED, Kagan JC, Amor JC, Kahn RA, et al. (2005) A Gterminal translocation signal required for Dot/Icm-dependent delivery of the Legionella RalF protein to host cells. Proc Natl Acad Sci U S A 102: 826-831.

53. Burstein D, Zusman T, Degtyar E, Viner R, Segal G, et al. (2009) Genome-scale identification of Legionella pneumophila effectors using a machine learning approach. PLoS Pathog 5: e1000508.

54. Truscott KN, Wiedemann N, Rehling P, Muller H, Meisinger C, et al. (2002) Mitochondrial import of the ADP/ATP carrier: the essential TIM complex of the intermembrane space is required for precursor release from the TOM complex. Mol Cell Biol 22: 7780-7789.

55. Ryan MT, Muller H, Pfanner N (1999) Functional staging of ADP/ATP carrier translocation across the outer mitochondrial membrane. J Biol Chem 274: 20619-20627.

56. Kutik S, Rissler M, Guan XL, Guiard B, Shui G, et al. (2008) The translocator maintenance protein Tam41 is required for mitochondrial cardiolipin biosynthesis. J Cell Biol 183: 1213-1221.

57. Smith CP, Thorsness PE (2008) The molecular basis for relative physiological functionality of the ADP/ATP carrier isoforms in Saccharomyces cerevisiae. Genetics 179: $1285-1299$

58. Cavero S, Traba J, Del Arco A, Satrustegui J (2005) The calcium-dependent $\mathrm{ATP}-\mathrm{Mg} / \mathrm{Pi}$ mitochondrial carrier is a target of glucose-induced calcium signalling in Saccharomyces cerevisiae. Biochem J 392: 537-544.

59. Traba J, Satrustegui J, del Arco A (2009) Characterization of SCaMC-3-like/ slc25a41, a novel calcium-independent mitochondrial ATP-Mg/Pi carrier. Biochem J 418: 125-133.

60. Marzo I, Brenner C, Zamzami N, Jurgensmeier JM, Susin SA, et al. (1998) Bax and adenine nucleotide translocator cooperate in the mitochondrial control of apoptosis. Science 281: 2027-2031.

61. Palmieri F, Indiveri C, Bisaccia F, Iacobazzi V (1995) Mitochondrial metabolite carrier proteins: purification, reconstitution, and transport studies. Methods Enzymol 260: 349-369.

62. Kol S, Nouwen N, Driessen AJ (2008) Mechanisms of YidC-mediated insertion and assembly of multimeric membrane protein complexes. J Biol Chem 283: 31269-31273.

63. Xie K, Dalbey RE (2008) Inserting proteins into the bacterial cytoplasmic membrane using the Sec and YidC translocases. Nat Rev Microbiol 6: 234-244.

64. Ninio S, Zuckman-Cholon DM, Cambronne ED, Roy CR (2005) The Legionella IcmS-IcmW protein complex is important for Dot/Icm-mediated protein translocation. Mol Microbiol 55: 912-926.

65. Bardill JP, Miller JL, Vogel JP (2005) IcmS-dependent translocation of SdeA into macrophages by the Legionella pneumophila type IV secretion system. Mol Microbiol 56: 90-103.

66. Vincent CD, Vogel JP (2006) The Legionella pneumophila IcmS-LvgA protein complex is important for Dot/Icm-dependent intracellular growth. Mol Microbiol 61: 596-613.

67. Huang L, Boyd D, Amyot WM, Hempstead AD, Luo ZQ, et al. (2011) The E Block motif is associated with Legionella pneumophila translocated substrates. Cell Microbiol 13: 227-245

68. Tusnady GE, Simon I (2001) The HMMTOP transmembrane topology prediction server. Bioinformatics 17: 849-850.

69. Sonnhammer EL, von Heijne G, Krogh A (1998) A hidden Markov model for predicting transmembrane helices in protein sequences. Proc Int Conf Intell Syst Mol Biol 6: 175-182.

70. Knirsch M, Gawaz MP, Klingenberg M (1989) The isolation and reconstitution of the ADP/ATP carrier from wild-type Saccharomyces cerevisiae. Identification of primarily one type (AAC-2). FEBS Lett 244: 427-432.
71. Gawaz M, Douglas MG, Klingenberg M (1990) Structure-function studies of adenine nucleotide transport in mitochondria. II. Biochemical analysis of distinct AAC1 and AAC2 proteins in yeast. J Biol Chem 265: 14202-14208.

72. Heimpel S, Basset G, Odoy S, Klingenberg M (2001) Expression of the mitochondrial ADP/ATP carrier in Escherichia coli. Renaturation, reconstitution, and the effect of mutations on 10 positive residues. J Biol Chem 276: 11499-11506.

73. Spagnoletta A, De Santis A, Palmieri F, Genchi G (2002) Purification and characterization of the reconstitutively active adenine nucleotide carrier from mitochondria of Jerusalem artichoke (Helianthus tuberosus L.) tubers. J Bioenerg Biomembr 34: 465-472.

74. Dolce V, Scarcia P, Iacopetta D, Palmieri F (2005) A fourth ADP/ATP carrier isoform in man: identification, bacterial expression, functional characterization and tissue distribution. FEBS Lett 579: 633-637.

75. Fiermonte G, De Leonardis F, Todisco S, Palmieri L, Lasorsa FM, et al. (2004) Identification of the mitochondrial ATP-Mg/Pi transporter. Bacterial expression, reconstitution, functional characterization, and tissue distribution. J Biol Chem 279: 30722-30730.

76. Maeno E, Ishizaki Y, Kanaseki T, Hazama A, Okada Y (2000) Normotonic cell shrinkage because of disordered volume regulation is an early prerequisite to apoptosis. Proc Natl Acad Sci U S A 97: 9487-9492.

77. Zamaraeva MV, Sabirov RZ, Maeno E, Ando-Akatsuka Y, Bessonova SV, et al. (2005) Cells die with increased cytosolic ATP during apoptosis: a bioluminescence study with intracellular luciferase. Cell Death Differ 12: 1390-1397.

78. Tsaousis AD, Kunji ER, Goldberg AV, Lucocq JM, Hirt RP, et al. (2008) A novel route for ATP acquisition by the remnant mitochondria of Encephalitozoon cuniculi. Nature 453: 553-556.

79. Dolezal P, Dagley MJ, Kono M, Wolynec P, Likic VA, et al. (2010) The essentials of protein import in the degenerate mitochondrion of Entamoeba histolytica. PLoS Pathog 6: e1000812.

80. Fritz-Laylin LK, Prochnik SE, Ginger ML, Dacks JB, Carpenter ML, et al (2010) The genome of Naegleria gruberi illuminates early eukaryotic versatility. Cell 140: 631-642.

81. Likic VA, Dolezal P, Celik N, Dagley M, Lithgow T (2010) Using hidden markov models to discover new protein transport machines. Methods Mol Biol 619: 271-284.

82. Eddy SR (1998) Profile hidden Markov models. Bioinformatics 14: 755-763.

83. Arnold K, Bordoli L, Kopp J, Schwede T (2006) The SWISS-MODEL workspace: a web-based environment for protein structure homology modelling. Bioinformatics 22: 195-201.

84. Thompson JD, Gibson TJ, Plewniak F, Jeanmougin F, Higgins DG (1997) The CLUSTAL_X windows interface: flexible strategies for multiple sequence alignment aided by quality analysis tools. Nucleic Acids Res 25: 4876-4882.

85. Chan NC, Lithgow T (2008) The peripheral membrane subunits of the SAM complex function codependently in mitochondrial outer membrane biogenesis. Mol Biol Cell 19: 126-136.

86. Daum G, Bohni PC, Schatz G (1982) Import of proteins into mitochondria. Cytochrome b2 and cytochrome c peroxidase are located in the intermembrane space of yeast mitochondria. J Biol Chem 257: 13028-13033.

87. Vergnolle MA, Alcock FH, Petrakis N, Tokatlidis K (2007) Mutation of conserved charged residues in mitochondrial TIM10 subunits precludes TIM10 complex assembly, but does not abolish growth of yeast cells. J Mol Biol 371: $1315-1324$

88. Foo JH, Culvenor JG, Ferrero RL, Kwok T, Lithgow T, et al. (2010) Both the p33 and p55 subunits of the Helicobacter pylori VacA toxin are targeted to mammalian mitochondria. J Mol Biol 401: 792-798.

89. Gentle I, Gabriel K, Beech P, Waller R, Lithgow T (2004) The Omp85 family of proteins is essential for outer membrane biogenesis in mitochondria and bacteria. J Cell Biol 164: 19-24.

90. Newton HJ, Sansom FM, Bennett-Wood V, Hartland EL (2006) Identification of Legionella pneumophila-specific genes by genomic subtractive hybridization with Legionella micdadei and identification of $\operatorname{lp} E$, a gene required for efficient host cell entry. Infect Immun 74: 1683-1691

91. Newton HJ, Sansom FM, Dao J, Cazalet C, Bruggemann H, et al. (2008) Significant role for $l a d C$ in initiation of Legionella pneumophila infection. Infect Immun 76: 3075-3085.

92. Hornung V, Bauernfeind F, Halle A, Samstad EO, Kono H, et al. (2008) Silica crystals and aluminum salts activate the NALP3 inflammasome through phagosomal destabilization. Nat Immunol 9: 847-856.

93. Fiermonte G, Dolce V, Palmieri F (1998) Expression in Escherichia coli, functional characterization, and tissue distribution of isoforms $\mathrm{A}$ and $\mathrm{B}$ of the phosphate carrier from bovine mitochondria. J Biol Chem 273: 22782-22787.

94. Drgon T, Sabova L, Nelson N, Kolarov J (1991) ADP/ATP translocator is essential only for anaerobic growth of yeast Saccharomyces cerevisiae. FEBS Lett 289: 159-162. 